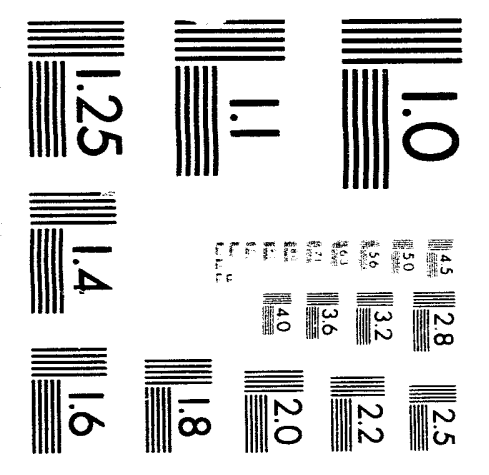



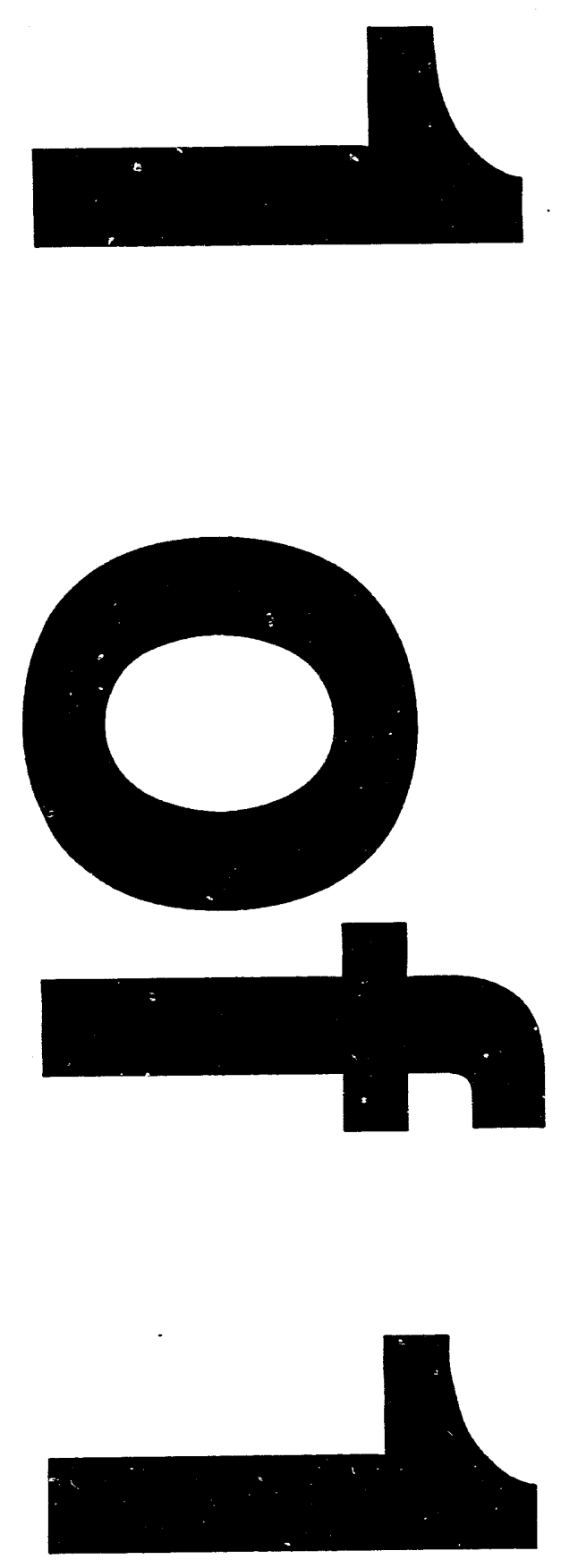
ANL/APS/IN/VIB-93/6

May 1993

\title{
THE EFFECTS OF THE PEDESTAL/FLOOR INTERFACE ON THE DYNAMIC CHARACTERISTICS OF THE STORAGE RING GIRDER SUPPORT ASSEMBLIES
}

\author{
by \\ J. A. Jendrzejczyk, S. S. Chen, S. Zhu, D. Mangra, and R. K. Smith \\ Argonne National La'̈oratory
}

\section{INTRODU ¿TION}

To avoid unacceptable vibration of the storage ring quadrupoles, and to ensure that the established vibration criteria are satisfied, the philosophy from inception of the APS has been (1) to locate and design the machine to minimize motion of the storage ring basemat and, (2) following construction, to monitor machine operation and user experiments to ensure that vibration sources are not introduced. In particular, the following design guidelines/goals have been established:

- choose a site location that is quiet in the sense that ambient ground motion is low;

- as possible, use distance to isolate the experimental hall and storage ring from potential noise sources (for example, utility building and cooling towers);

- ensure that the surfaces of roads in the near vicinity of the expf cimental hall are smooth; control traffic speed and, as necessary, restrict the operation of heavy vehicles;

- require initial balancing of all rotating machinery and periodic monitoring to ensure that such machinery stays in balance;

- design the storage ring girder support assemblies to be as rigid as possible within design constraints;

- as possible, use damping to minimize resonant vibration response;

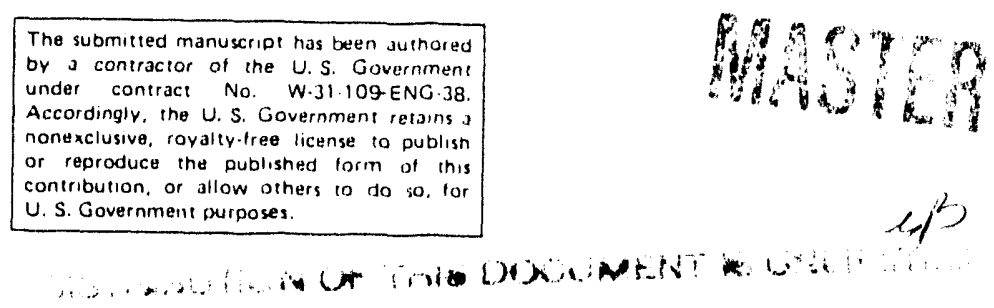


- $\quad$ impose requirements on experiments, brought in by user groups, to ensure that they do not represent vibration sources.

This report addresses the design of the storage ring girder support assemblies, and, specifically, the effect of the pedestal/floor interface on the dynamic characteristics (i.e., resonant frequencies, damping, and mode shape).

With the exception of vibration excitation resulting from coolant flow through the magnets or the result of pulsing of the magnets (both of which are expected not to be of concern), any vibration of the quadrupoles will be the result of storage ring basemat motion which is transmitted to the quadrupoles via the magnet support assemblies. If the support assemblies could be designed to be perfectly rigid, the quadrupoles could reasonably be assumed to follow the motion of the basemat. In reality, the support assemblies represent dynamic systems, with the potential for resonant excitation and response magnification.

Measurements have shown that the site is quiet from the standpoint of ambient ground motion [1]; measured amplitudes are within the APS vibration criteria for the storage ring quadrupoles. The measurements have also shown that ground motion is typically attenuated in the response of the various floor slabs or basemats [2]. From these results, it is further shown that the major contributions to ground motion, and hence to basemat motion, are at low frequencies (say, $<10 \mathrm{~Hz}$ ). Therefore, to avoid the potential for resonant vibration and amplification of low-frequency basemat motion, the design objective for the storage ring girder support assemblies, as indicated above, was to design the assemblies to be as rigid as possible within design constraints; ideally, one would also like to have the inherent damping to be high.

The design constraints are (1) the height of the beamline above the floor and (2) the requirement that the support system include a three-point support with alignment and leveling devices. The height of the beamline above the floor sets the center of mass of the magnets at $1.4 \mathrm{~m}$. After several design iterations, wedge-type jacks were selected as the alignment device, and shims between the pedestal and floor were chosen as the means to level the girders.

A vibration study of the APS storage ring girder/support assembly with wedgetype alignment jacks was performed and reported [3]. The results of the study indicated that, relative to the APS vibration criteria, the design was acceptable from a vibrations standpoint. However, the test set-up was not prototypic, with the main deviations from prototypicality observed to be the following:

- The pedestals were not grouted to the floor. 
- Magnets were simulated by concrete shielding blocks that were simply placed on the girder and not securely fastened.

- The floor on which the girder was mounted was relatively thin $(\sim 6$ in. thick) and, consequently, more flexible than the storage ring basemat (24 in. thick).

Discounting frequencies associated with the dynamics of the shielding blocks, only one dominant frequency $(9.6 \mathrm{~Hz})$ was measured in the transverse-to-beamline $(\mathrm{X})$ direction; no dominant beamline $(\mathrm{Z})$ direction frequencies were measured. The measured mode shape (see Fig. 1a) demonstrated that the lowest mode frequency was associated with the girder and pedestal behaving as rigid bodies with rotation (effectively torsional springs and dampers) at both the girder/jack/pedestal and pedestal/shims/floor interfaces; see the sketch in Fig. 1b. Measured damping values ranged from 1.7 to $2.6 \%$ of critical damping. Tests were also performed with the girder unloaded. In this case, frequencies of 33.5 and $51.5 \mathrm{~Hz}$ were measured in the $\mathrm{X}$ - and Z-directions, respectively.

In the discussion of the results from the previous study, it was suggested that grouting the pedestals to the floor could be expected to increase the lowest mode frequency, but that it was not possible to predict how much. It was also noted in the discussion that for the system under consideration, that is, a large mass (magnets weighing 12,000 to $14,000 \mathrm{lb}$ ), having a high center of mass (1.4 m above the floor) and mounted on a three-point support, the lowest mode frequency would inherently be in the range $<20 \mathrm{~Hz}$, and that it would be difficult to raise it above $20 \mathrm{~Hz}$.

While the previous study provided valuable insights, follow-on testing was recommended with the objective to test a more prototypic set-up and to investigate the effect of the two interfaces (girder/jack/pedestal and pedestal/floor) on the dynamic characteristics of the support system. In particular, additional testing was recommended to determine (a) how grouting would effect the dynamic characteristics of the system and (b) what effect floor thickness has on the dynamic response.

Magnets were not available for installation on the girder. Therefore, an unloaded girder was tested. Since we are only interested in the comparative effects of the grout it was not necessary to simulate the actual loaded girder system. The weight of the magnets may have some effect on the flexibility and damping at the two interfaces, but it is not expected to be an appreciable effect. The increase in the mass and mass moment of inertia with the magnets mounted on the girder will significantly reduce the rigid body mode frequencies of interest; results from the previous study using concrete shielding blocks to simulate the magnets showed that 
the lowest X-direction frequency was reduced from $33.5 \mathrm{~Hz}$ (unloaded girder) to $9.6 \mathrm{~Hz}$ (loaded girder).

\section{TEST OBJECTIVES}

The test objectives were to (a) measure the dynamic characteristics (resonant frequencies, damping, and mode shapes) of the girder/support assembly for each of the three pedestal-to-floor mounting methods (shims alone, shims and grout, and grout alone), and (b) based on the test results, make a recommendation relative to the mounting method.

\section{TEST SET-UP}

The test set-up is illustrated in Fig. 2. Two pedestal sets, designated pedestal sets $\mathrm{A}$ and $\mathrm{B}$ were mounted to the floor in the Bldg. 335 highbay using prototypic mounting methods, and leveled. Two Section 5 girders (designated Girder A and Girder B) were then mounted on the pedestals and leveled. The mounting and leveling were performed by APS personnel. The girders each weigh approximately $4,000 \mathrm{lb}$ and each pedestal weighs approximately $550 \mathrm{lb}$. The highbay floor was nominally 16 in. thick.

An inertial-mass shaker was attached to the girder and used to excite the girder/support system in both the X- (transverse to beamline) and Z- (beamline) directions. It should be noted that the shaker has an inherent resonant frequency at approximately $18 \mathrm{~Hz}$.

Six different configuration/mounting-methods were tested as described in Table 1. For each configuration/mounting method the girder was excited with the shaker in three different locations/orientations: in the X-direction near the two-jack and one-jack ends, and in the Z-direction. Consequently, a total of eighteen test were performed.

For each of the tests, five piezoelectric accelerometers (PCB model 393) were mounted on the girder/support assembly and distributed vertically to measure mode shape. In particular, the five accelerometers were located at the girder top, girder center, girder bottom, pedestal top, and pedestal bottom. A sixth accelerometer (also, PCB model 393) was mounted on the floor. Accelerometers are shown mounted on the structural system in the photographs of Figs. 3-5; the shaker mounted on the girder is also shown in Fig. 4. The accelerometer signals were double-integrated to provide displacement response. 
Table 1. Test Configurations

\begin{tabular}{cc}
$\begin{array}{c}\text { Girder/ } \\
\text { Pedestal Set }\end{array}$ & $\begin{array}{c}\text { Pedestal/Floor } \\
\text { Interface }\end{array}$ \\
\cline { 2 - 2 } A/A & shims alone \\
B/B & shims alone \\
A/A & shims and grout \\
B/A & shims and grout \\
A/B & grout alone \\
B/B & grout alone
\end{tabular}

\section{TEST PROCEDURE}

For each of the eighteen test runs, the following test procedure was followed:

- excite the system with 1-to- $100 \mathrm{~Hz}$ random force with the objective to identify resonant frequencies;

- excite the system with $25-$ to- $100 \mathrm{~Hz}$ random force with the objective to obtain better resolution in identifying resonant frequencies;

- excite the system at the identified resonant frequencies with eight different force levels with the objectives of determining mode shape and linearity;

- perform sine sweeps through the resonant frequencies at two different force levels with the objectives of determining damping and evaluating the linearity of the damping.

The bolts attaching the wedge-type alignment jacks to the girder were not adjusted (tightened or loosened) during the test series so as to rule out bolt tensioning as a test variable.

\section{TYPICAL TEST RESULTS}

A set of results from tests of Girder A, mounted on pedestal set B, with the shaker located near the two-jack end, and excitation in the $\mathrm{X}$ direction is given in Figs. 6-8 and Table 2. This set of results is typical of the results obtained from all test runs and serves to illustrate the data reduction and analysis procedures that were applied. 
In Fig. 6, the frequency spectrum of the response to 0 -to-100 $\mathrm{Hz}$ random excitation is given. Two dominant frequencies $:-1 \mathrm{e}$ observed in the PSD. The $18-\mathrm{Hz}$ frequency is the resonant frequency of the shaker. The other dominant frequency is the support system resonant frequency at $41 \mathrm{~Hz}$.

The frequency spectrum of the response to $25-$ to- $100 \mathrm{~Hz}$ random excitation is given in Fig. 7. As no system frequencies below $25 \mathrm{~Hz}$ were identified in Fig. 6, this frequency spectrum provides better resolution in the excitation frequency range. Again, the support system frequency at $41 \mathrm{~Hz}$ is readily identified.

The RMS displacement response to sinusoidal excitation of the girder/support system at the system resonant frequency for this test run $(41 \mathrm{~Hz})$ was measured for eight different excitation force levels. RMS response to a given force level $(0.089 \mathrm{lb}$ force) is given in Table 2 .

Table 2. RMS response to sinusoidal excitation at the system resonant frequency (Excitation level: $0.089 \mathrm{lb}$ )

\begin{tabular}{|c|c|c|}
\hline $\begin{array}{l}\text { Accelerometer } \\
\text { Location } \\
\end{array}$ & $\begin{array}{l}\text { Height above } \\
\text { Floor (in.) }\end{array}$ & $\begin{array}{l}\text { RMS Displacement } \\
(\mu \mathrm{m})\end{array}$ \\
\hline girder top & 32.0 & 3.64 \\
\hline girder center & 23.5 & 2.46 \\
\hline girder bottom & 18.0 & 1.30 \\
\hline pedestal top & 9.0 & 0.115 \\
\hline pedestal bottom & 2.8 & 0.080 \\
\hline floor & 0.0 & 0.051 \\
\hline
\end{tabular}

The data of Table 2 are ultimately plotted, together with data from other excitation force levels, to give information relative to the mode shape.

A typical swept sine result is given in Fig. 8. The response is to a given excitation force level and the different curves correspond to the different accelerometer locations on the girder/support system. Damping factor is determined from the response curve using the half-power bandwidth method; results are obtained for two excitation force levels. 


\section{SUMMARY/DISCUSSION OF TEST RESULTS}

Resonant frequencies (stiffness), Resonant frequencies for the different girder/pedestal/mounting configurations are summarized in Table 3. In Table 3, results from the earlier study [3], with the girder unloaded and "shims alone" for the pedestal/floor interface, are included for comparison.

From the results of Table 3, it can be concluded that grouting increases the resonant frequencies (stiffness) of the system. The resonant frequency associated with the fundamental X-direction mode increased by approximately $5 \mathrm{~Hz}$, while the frequency associated with the Z-direction mode increased approximately $30 \mathrm{~Hz}$. We have no explanation why the frequencies associated with configurations "A/A-shims alone" and "A/A-shims and grout" are approximately $5 \mathrm{~Hz}$ lower than corresponding tests with girder $\mathrm{B}$, for both the X- and Z-direction modes; for the grout-alone interface condition, the test results from girders $\mathrm{A}$ and $\mathrm{B}$ are in good agreement. The frequencies do not change significantly when comparing the "shims and grout" and "grout alone" conditions.

A comparison of the X-and Z-direction mode frequencies for the "shims alone" conditions of this test with the results of the previous study for the unloaded girder show the frequencies to be in good agreement. Since the previous study was with a 6 in. concrete floor and the present study with a $>16$ in. concrete floor, it can be concluded that within this range (i.e., floor thickness $>6$ in.), the thickness of the floor has a negligible effect on the system dynamics.

Table 3. Summary of test results (resonant frequencies and damping)

\begin{tabular}{|c|c|c|c|c|c|}
\hline \multirow[b]{2}{*}{$\begin{array}{c}\text { Girder/ } \\
\text { Ped. Set }\end{array}$} & \multirow[b]{2}{*}{$\begin{array}{c}\text { Ped./Floor } \\
\text { Interface }\end{array}$} & \multicolumn{2}{|c|}{ X-mode } & \multicolumn{2}{|c|}{ Z-mode } \\
\hline & & $f_{n}$ & $\zeta$ & $\mathrm{f}_{\mathrm{n}}$ & $\zeta$ \\
\hline $\mathrm{A} / \mathrm{A}$ & Shims alone & 29.8 & $0.77-0.98$ & 45.2 & $1.65-1.72$ \\
\hline $\mathrm{B} / \mathrm{B}$ & Shims alone & 34.7 & $0.97-1.10$ & 50.8 & $1.99-2.42$ \\
\hline Ref. 1 & Shims alone & 33.5 & - & 51.5 & - \\
\hline $\mathrm{A} / \mathrm{A}$ & Shims \& grout & 35.0 & $0.72-0.78$ & 74.2 & $1.41-1.49$ \\
\hline $\mathrm{B} / \mathrm{A}$ & Shims \& grout & 40.1 & 1.04-1.09 & 82.5 & $1.41-1.46$ \\
\hline $\mathrm{A} / \mathrm{B}$ & Grout alone & 40.5 & $0.76-0.81$ & 79.5 & $1.63-1.74$ \\
\hline $\mathrm{B} / \mathrm{B}$ & Grout alone & 41.8 & $0.74-0.84$ & 82.5 & $1.48-1.62$ \\
\hline
\end{tabular}

Damping $\zeta$ is given as percent of critical damping. 
Damping. Damping values, computed from the swept sine data using the half-power bandwidth method, are also given in Table 3. The damping was obtained from measurements made at two different excitation force levels. The damping was determined to be essentially independent of force level, and thus judged to behave linearly (i.e., amplitude independent). The range on damping given in Table 3 corresponds to the low and high values measured.

In comparing damping values measured in the various tests it can be observed that for the X-direction modes the damping values for both girders $\mathrm{A}$ and $\mathrm{B}$ are lower with shims and grout. With shims alone or grout alone the damping values are approximately the same. For the Z-direction modes, the damping values with shims alone are higher than those with grout alone.

While there are some variances in comparing measured damping values for the different tests, as discussed above, in general, it is reasonable to assume that damping is independent of the pedestal/floor interface conditions tested. For the Zdirection mode damping i: 1.5 to 2.5 times greater than for the X-direction mode; damping, as a percentage of critical damping, for the $\mathrm{X}$-direction mode varies from 0.72 to 1.10 and for the Z-direction mode varies from 1.41 to 2.42. Because of the very small motions, it should not be surprising that the grout did not have a significant effect on damping.

Mode shape. For each test run, mode shapes were determined for a range of excitation force levels by plotting RMS displacement as a function of measurement location; an example is given in Fig. 9 for girder A mounted on pedestal set A and excited in the X-direction. To investigate the linearity of the system, and to define a mode shape, the displacement response data from a given test run were normalized to a value of one at the "girder top" location and plotted in a composite plot. Results for the X-direction mode are given in Figs. 10-15; results for the Z-direction mode are given in Figs. 16-21. There are some variances, which can be attributed to measurement errors because of the very small displacements being measured. However, in general, the normalized curves collapse on one another indicating that the system is behaving linearly for these small motions.

The X-direction mode shape for the case of "shims alone" is in qualitative agreement with the mode shape measured in the previous study [1]; compare Fig. 10 with Fig. 1a. Again, the girder and pedestals act as rigid bodies with the girder/jack/pedestal and pedestal/floor interfaces acting as rotational joints with torsional springs and dampers. Relative motion is greater at the girder/jack/ pedestal support, indicating that that interface is more flexible.

Figure 22 was prepared to allow for a comparison of the X-direction mode shapes for the tests with and without grout, that is, a comparison of the mode shape 
given in Fig. 10 (shims alone) with the mode shapes given in Figs. 12 (shims and grout) and 14 (grout alone). From Fig. 22 one can readily observe the stiffening effect of the grout. In particular, with the grout there is only small rotation at the floor interface. However, because the girder/jack/pedestal interface remains the "weak link," the stiffening provided by the grout has only a small effect on the resonant frequency, increasing it by approximately $5 \mathrm{~Hz}$.

The Z-direction mode shapes differs from the X-direction mode shapes in that the mode shape shows that the girder is translating rather than rotating at the girder/jack/pedestal interface; see Fig. 23. In this case, in determination of the effective stiffness for that mode, the pedestal/floor interface may be considered controlling, as rotation is indicated at that interface. The difference in "controlling interfaces" explains why the grout is more effective in increasing the effective stiffness for the Z-direction mode relative to the X-direction mode.

Figure 24, which is analogous to Fig. 22, was prepared to allow for a comparison of the Z-direction mode shapes for the tests with and without grout; that is, it compares the mode shape given in Fig. 16 (shims alone) with the mode shapes given in Figs. 18 (shims and grout) and 20 (grout alone). As in Fig. 22, from Fig. 24 one can readily observe the stiffening effect of the grout at the floor interface; rotation at that interface is restricted.

Equivalent single-degree-of-freedom model. Further insights into the dynamics of the girder/support system can be obtained by considering an equivalent single-degree-of-freedom model. Such a model is feasible since the system exhibits a single mode frequency in each of the X-and Z-directions. The equivalent singledegree-of-freedom model is given in Fig. 25, together with a nomenclature and equations relating the various variables.

The amplitude $\mathrm{X}$ of the response of the system to a sinusoidal force of amplitude $\mathrm{F}_{0}$ can be written as

$$
\frac{X}{X_{0}}=\frac{1}{\sqrt{\left[1-\left(\frac{\omega}{\omega_{n}}\right)^{2}\right]^{2}+\left[2 \zeta\left(\frac{\omega}{\omega_{n}}\right)\right]^{2}}}
$$

where,

$$
\mathrm{X}_{\mathrm{o}}=\frac{\mathrm{F}_{0}}{\mathrm{k}_{\mathrm{e}}}
$$


When the system is excited at resonance, $\omega=\omega_{n}$ and $X=X_{n}$. This allows solving Eq. (1) for an equivalent spring-constant and equivalent mass ( $x$ is considered to be a generalized coordinate in this analysis),

$$
\begin{gathered}
\mathrm{k}_{\mathrm{e}}=\frac{\mathrm{F}_{0}}{\mathrm{X}_{\mathrm{n}} 2 \zeta} \\
\mathrm{m}_{\mathrm{e}}=\frac{\mathrm{K}_{\mathrm{e}}}{\left(2 \pi \mathrm{f}_{\mathrm{n}}\right)^{2}} .
\end{gathered}
$$

In Eq. (3) we will substitute for $F_{0}$ the maximum force for a given test, and for $X_{n}$ the measured RMS displacement at the top of the pedestal; the damping value $\zeta$ will be taken to be the average of the damping range given in Table 3 . The results are summarized in Table 4. In comparing the equivalent single-degree-of-freedom models for the different test configurations, the equivalent mass of the model for the shims alone configuration is used as the basis. The corresponding equivalent stiffnesses can be compared and their ratios are given in Table 4. Based on the stiffness ratio, the frequency ratios can be calculated; these are also given in Table 4 together with the frequency ratios from measurements. The frequency ratios from the equivalent models and measurement are in good agreement. This verifies that a single-degree-of-freedom model is a good model for the system.

From the results tabulated in Table 4, one can get a qualitative feel for the increase in equivalent stiffness provided by the grout. In particular in the Xdirection stiffness is increased by a factor of 1.25 to 2.03 and in the Z-direction from 2.65 to 3.04 .

Equivalent two-degree-of-freedom model. The system can also be modeled as a two-degree-of-freedom system as shown in Fig. $26 . \mathrm{m}_{1}$ and $\mathrm{m}_{2}$ represent the masses of support and girder; they are assumed to be 2,450 lb and $4,000 \mathrm{lb}$ respectively. The displacements at the top of the pedestal and girder are $u_{1}$ and $\mathrm{u}_{2}$. The equations of motion are

$$
\begin{gathered}
\mathrm{m}_{1} \ddot{\mathrm{u}}_{1}+\left(\mathrm{k}_{1}+\mathrm{k}_{2}\right) \mathrm{u}_{1}-\mathrm{k}_{2} \mathrm{u}_{2}=0 \\
\mathrm{~m}_{2} \ddot{\mathrm{u}}_{2}-\mathrm{k}_{2} \mathrm{u}_{1}+\mathrm{k}_{2} \mathrm{u}_{2}=0 .
\end{gathered}
$$

From the equations of motion, the lowest natural frequency $f_{n}$ can be calculated: 
Table 4. Equivalent single-degree-of-freedom model

\begin{tabular}{|c|c|c|c|c|c|c|c|c|c|c|c|c|c|}
\hline $\begin{array}{c}\text { Test } \\
\text { no. }\end{array}$ & $\begin{array}{l}\text { Girder/ } \\
\text { ped. set }\end{array}$ & $\begin{array}{l}\text { Girder/ } \\
\text { floor } \\
\text { interface }\end{array}$ & $\begin{array}{c}f_{n} \\
(H z)\end{array}$ & $\eta$ & $\begin{array}{c}\mathrm{X}_{\mathrm{n}} \times 10^{6} \\
(\mathrm{~m})\end{array}$ & $\begin{array}{c}F_{0} \\
(\mathrm{lb})\end{array}$ & $\begin{array}{c}\mathrm{k}_{\mathrm{e}} \mathrm{q} \times 10^{-6} \\
(\mathrm{lb} / \mathrm{in} .)\end{array}$ & $\begin{array}{l}\mathrm{m}_{\mathrm{e}} \mathrm{q} \\
(\mathrm{lb})\end{array}$ & $\begin{array}{l}\text { Shims } \\
\mathrm{k} / \mathrm{k}_{\text {shim }}\end{array}$ & $\begin{array}{l}\text { Shims } \\
\text { \& grout } \\
\mathrm{k} / \mathbf{k}_{\text {shim }}\end{array}$ & $\begin{array}{c}\text { Grout } \\
\mathrm{k} / \mathrm{k}_{\text {shim }}\end{array}$ & $\begin{array}{c}\text { Frequency } \\
\text { ratio based } \\
\text { on } k_{e} \\
\end{array}$ & $\begin{array}{c}\text { Frequency } \\
\text { ratio based } \\
\text { on } f_{n} \\
\end{array}$ \\
\hline \multicolumn{14}{|c|}{ X-direction mode (downstream with single-jack end data): } \\
\hline 1 & A/A & $\begin{array}{l}\text { Shims } \\
\text { alone }\end{array}$ & 29.8 & 0.0088 & 4.13 & 0.156 & 0.05 & 600 & 1.00 & & & 1.0 & 1.0 \\
\hline 1 & $\mathrm{~B} / \mathrm{B}$ & $\begin{array}{l}\text { Shims } \\
\text { alone }\end{array}$ & 34.7 & 0.0104 & 2.4 & 0.132 & 0.07 & 545 & 1.00 & & & 1.0 & 1.0 \\
\hline 2 & A/A & $\begin{array}{c}\text { Shims \& } \\
\text { grout }\end{array}$ & 35.0 & 0.0075 & 0.771 & 0.123 & 0.27 & 2156 & & 1.50 & & 1.22 & 1.17 \\
\hline 3 & $\mathrm{~B} / \mathrm{A}$ & $\begin{array}{l}\text { Shims \& } \\
\text { grout }\end{array}$ & 40.1 & 0.0106 & 0.553 & 0.113 & 0.24 & 1489 & & 1.25 & & 1.12 & 1.16 \\
\hline 2 & $\mathrm{~B} / \mathrm{B}$ & $\begin{array}{l}\text { Grout } \\
\text { alone }\end{array}$ & 41.8 & 0.0079 & 0.396 & 0.108 & 0.44 & 2453 & & & 1.40 & 1.18 & 1.16 \\
\hline 3 & $\mathrm{~A} / \mathrm{B}$ & $\begin{array}{l}\text { Grout } \\
\text { alone }\end{array}$ & 40.5 & 0.0078 & 0.507 & 0.111 & 0.36 & 2125 & & & 2.03 & 1.42 & 1.40 \\
\hline \multicolumn{14}{|c|}{ Z-direction mode: } \\
\hline 1 & A/A & $\begin{array}{c}\text { Shims } \\
\text { alone }\end{array}$ & 45.2 & 1.7 & 3.03 & 0.124 & 0.00031 & 1.46 & 1.00 & & & & \\
\hline 1 & $\mathrm{~B} / \mathrm{B}$ & $\begin{array}{l}\text { Shims } \\
\text { alone }\end{array}$ & 50.8 & 2.2 & 1.56 & 0.099 & 0.00036 & 1.38 & 1.00 & & & & \\
\hline 2 & $\mathrm{~A} / \mathrm{A}$ & $\begin{array}{l}\text { Shims \& } \\
\text { grout }\end{array}$ & 74.2 & 1.45 & 0.246 & 0.088 & 0.00314 & 5.58 & & 2.65 & & 1.63 & 1.64 \\
\hline 3 & $\mathrm{~B} / \mathrm{A}$ & $\begin{array}{l}\text { Shims \& } \\
\text { grout }\end{array}$ & 82.5 & 1.44 & 0.192 & 0.086 & 0.00395 & 5.67 & & 2.67 & & 1.63 & 1.62 \\
\hline 2 & $\mathrm{~B} / \mathrm{B}$ & $\begin{array}{l}\text { Grout } \\
\text { alone }\end{array}$ & 82.5 & 1.55 & 0.179 & 0.086 & 0.00392 & 5.63 & & & 2.82 & 1.68 & 1.56 \\
\hline 3 & $\mathrm{~A} / \mathrm{B}$ & $\begin{array}{l}\text { Grout } \\
\text { alone }\end{array}$ & 79.5 & 1.68 & 0.210 & 0.090 & 0.00323 & 5.00 & & & 3.04 & 1.74 & 1.83 \\
\hline
\end{tabular}

Note: $F_{0}$ is maximum RMS force for a given test; $X_{n}$ is measured RMS displacement at top of pedestal 


$$
\begin{aligned}
\left(2 \pi f_{n}\right)^{2}= & \frac{1}{2} \frac{m_{1} k_{2}+m_{2}\left(k_{1}+k_{2}\right)}{m_{1} m_{2}} \\
& -\frac{1}{2} \sqrt{\left(\frac{m_{1} m_{2}+m_{2}\left(k_{1}+k_{2}\right)}{m_{1} m_{2}}\right)^{2}-4 \frac{\left(k_{1}+k_{2}\right) k_{2}-k_{2}^{2}}{m_{1} m_{2}}}
\end{aligned}
$$

and the corresponding mode shape is

$$
\frac{\mathrm{u}_{2}}{\mathrm{u}_{1}}=\frac{\mathrm{k}_{1}+\mathrm{k}_{2}-\left(2 \pi \mathrm{f}_{\mathrm{n}}\right)^{2} \mathrm{~m}_{1}}{\mathrm{k}_{2}}
$$

From experimental data given in Figs. $10-21$, the amplitude ratio, $\mathrm{u}_{2} / \mathrm{u}_{1}$, can be calculated and the frequency is measured. With these two parameters and Eqs. 7 and 8, spring constants, $\mathrm{k}_{1}$ and $\mathrm{k}_{2}$, are calculated; see Table 5 . In addition, the stiffness ratios of $k_{1}$ with respect to the reference case with shims alone are also given. Because of the assumptions used in the model, it is difficult to define any specific parameter. However, some general trends are noted:

- The stiffness $\mathrm{k}_{2}$ varies from $5.4 \times 10^{6} \mathrm{lb} / \mathrm{ft}$ to $10.3 \times 10^{6} \mathrm{lb} / \mathrm{ft}$ in the $\mathrm{X}$ direction and from $27.1 \times 10^{6}$ to $54.6 \times 10^{6} \mathrm{lb} / \mathrm{ft}$ in the $\mathrm{Z}$ direction. $\mathrm{k}_{2}$

\begin{tabular}{|c|c|c|c|c|c|c|c|}
\hline \multirow[b]{3}{*}{ Girder } & \multirow[b]{3}{*}{ Support } & \multicolumn{6}{|c|}{ Spring Constant, $10^{-6} \mathrm{lb} / \mathrm{ft}$} \\
\hline & & \multicolumn{3}{|c|}{$\mathrm{X}$-Direction } & \multicolumn{3}{|c|}{ Z-Direction } \\
\hline & & $\mathrm{k}_{1}$ & $\mathbf{k}_{2}$ & $\begin{array}{c}\mathrm{k}_{1} \\
\text { ratio }\end{array}$ & $\mathbf{k}_{1}$ & $\mathrm{k}_{2}$ & $\begin{array}{c}\mathbf{k}_{1} \\
\text { ratio } \\
\end{array}$ \\
\hline \multirow{3}{*}{ A } & Shims alone & 27.2 & 5.4 & & 22.0 & 27.1 & \\
\hline & Shims and grout & 103.6 & 6.4 & 3.8 & 93.7 & 41.5 & 4.2 \\
\hline & Grout alone & 128.5 & 8.6 & 4.7 & 114.2 & 45.8 & 5.2 \\
\hline \multirow{3}{*}{$\mathrm{B}$} & Shims alone & 43.0 & 7.0 & & 25.5 & 43.5 & \\
\hline & Shims and grout & 59.3 & 10.3 & 1.37 & 115.6 & 51.3 & 4.5 \\
\hline & Grout alone & 135.3 & 8.3 & 3.1 & 105.9 & 54.6 & 4.2 \\
\hline
\end{tabular}
increases slightly with grout alone or shims and grout.

Table 5. Spring constants $\mathrm{k}_{1}$ and $\mathrm{k}_{2}$ for Girders A and B 
- The stiffnesses $\mathrm{k}_{1}$ are about the same in the $\mathrm{X}$ and $\mathrm{Z}$ directions. The values vary from $22 \times 10^{6} \mathrm{lb} / \mathrm{ft}$ to $135 \times 10^{6} \mathrm{lb} / \mathrm{ft}$. With the exception of Girder B with shims and grout, all others show that with grout alone or shims and grout, the stiffness $\mathrm{k}_{1}$ increases from 3.1 to 5.2 times.

Based on the two-degree-of-freedom model, it is shown that the increase of the natural frequency is due to the increase of the support rigidity by using grout.

\section{RECOMMENDATIONS}

As noted in the Introduction, a goal is to design the girder/support assembly to be as rigid (stiff) as possible. Therefore, incorporation of design changes that serve to increase the effective stiffness should be accommodated. The use of grout serves to increase the stiffness (as observed by increases in resonant frequencies) of the system while not significantly affecting damping; the increase in stiffness is most effective in the Z-direction. Therefore, it is recommended that epoxy grout be used between the APS storage ring girder pedestals and floor. From a dynamics standpoint, it is immaterial whether or not shims are included. The use of shims should be considered only from the point of view of alignment and installation.

\section{REFERENCES}

1. Jendrzejczyk, J. A., Nagy, Z., and Smith, R. K., "Ambient Ground Motion at the APS Site at Argonne National Laboratory over Extended Time Periods," APS Report LS-136 (December 1988)

2. Jendrzejczyk, J. A., Wambsganss, M. W., and Smith, R. K., "Vibration Response of the APS Linac Floor Slab to Ambient Ground Motion," Argonne National Laboratory Report ANL/APS/IN/VIB-92/1 (November 1991)

3. Jendrzejczyk, J. A., Wambsganss, M. W., and Smith, R. K., "Vibration Study of the APS Storage Ring Girder/Support Assembly Equipped with Wedge-Type Alignment Jacks," Argonne National Laboratory Report ANL/APS/IN/VIB-92/2 (February 1992) 


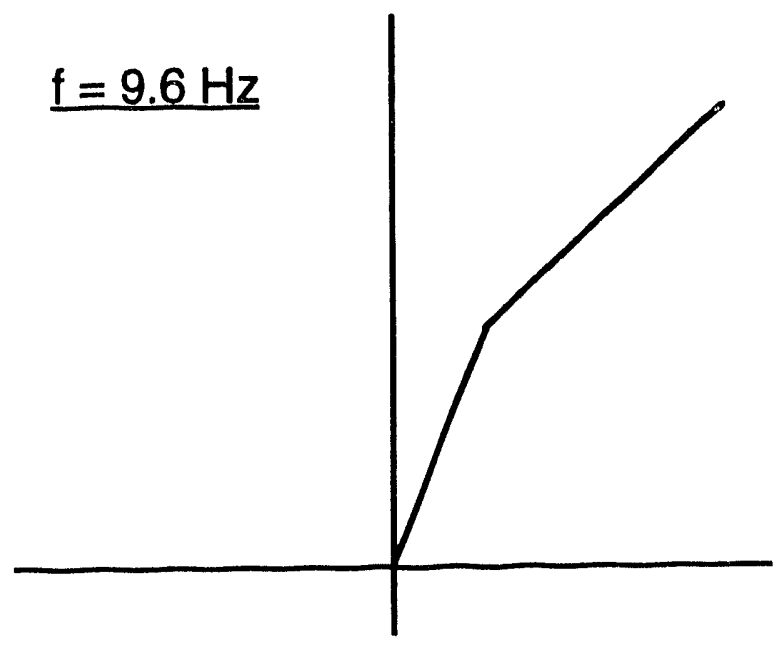

(a) Measured mode shape [1]

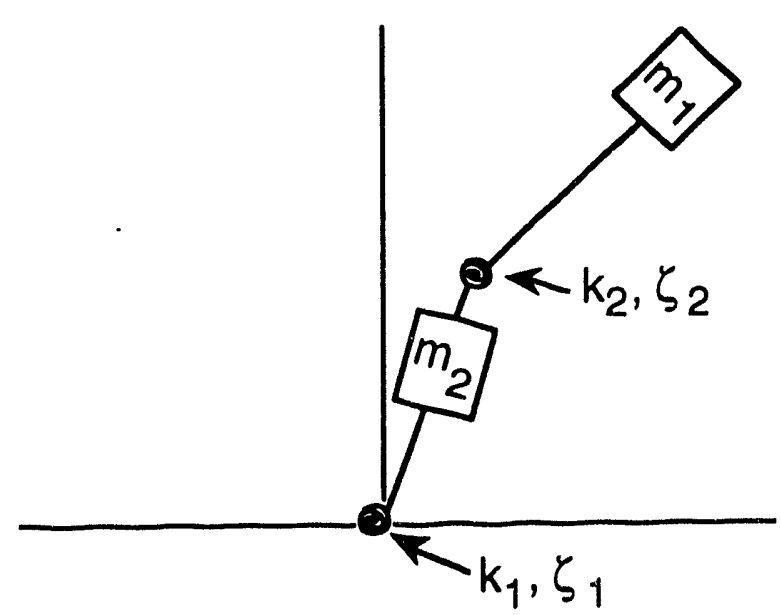

(b) Spring/damper/mass model

Fig. 1. X-direction mode 
Beam direction $\rightarrow$

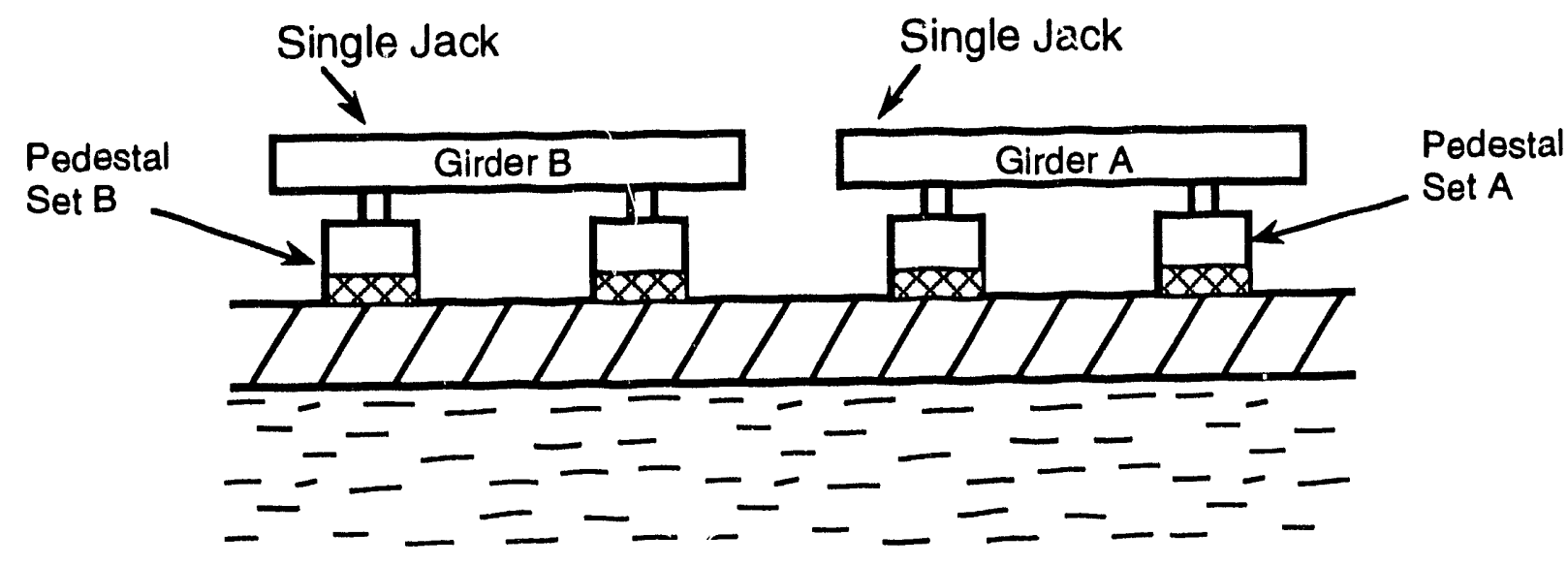

Fig. 2. Test set-up 


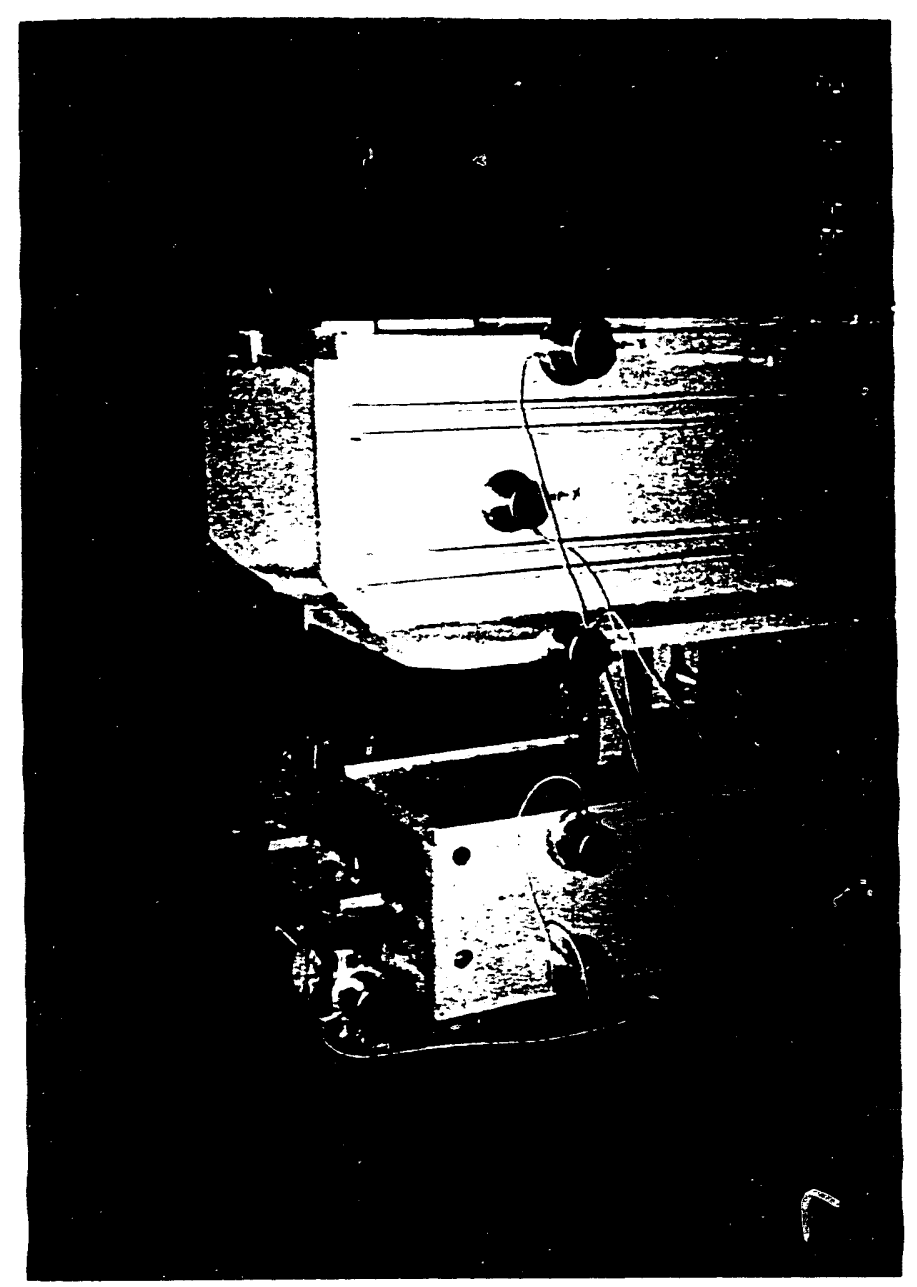

Fig. 3. Accelerometers located on girder/ pedestal system and oriented to measure X-direction response: Girder $\mathrm{A} /$ Pedestal set $\mathrm{A} /$ single-jack end

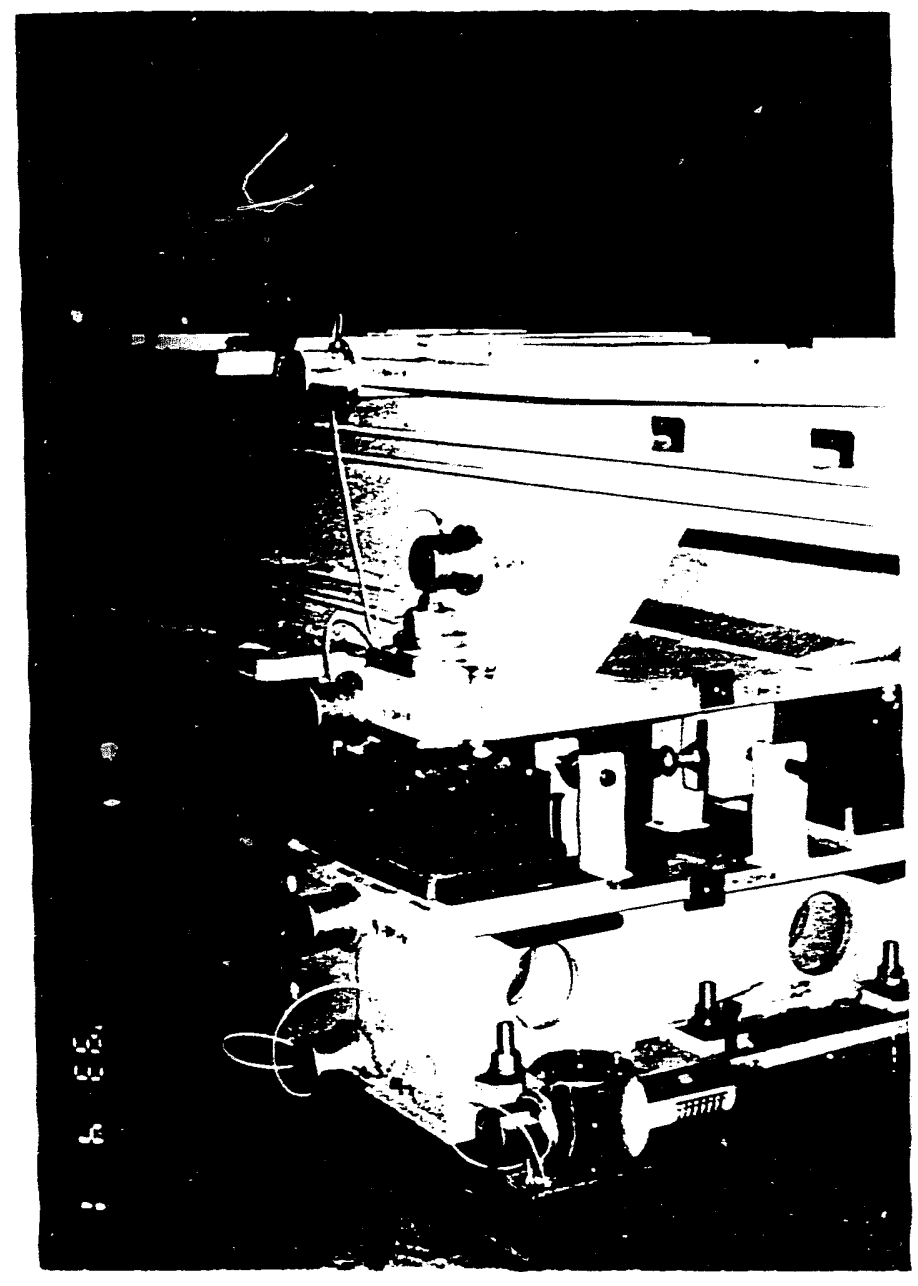

Fig. 4. Accelerometers and shaker located on girder/pedestal system and oriented to measure X-direction response: Girder A Pedestal set A/doub! $e$-jack end 


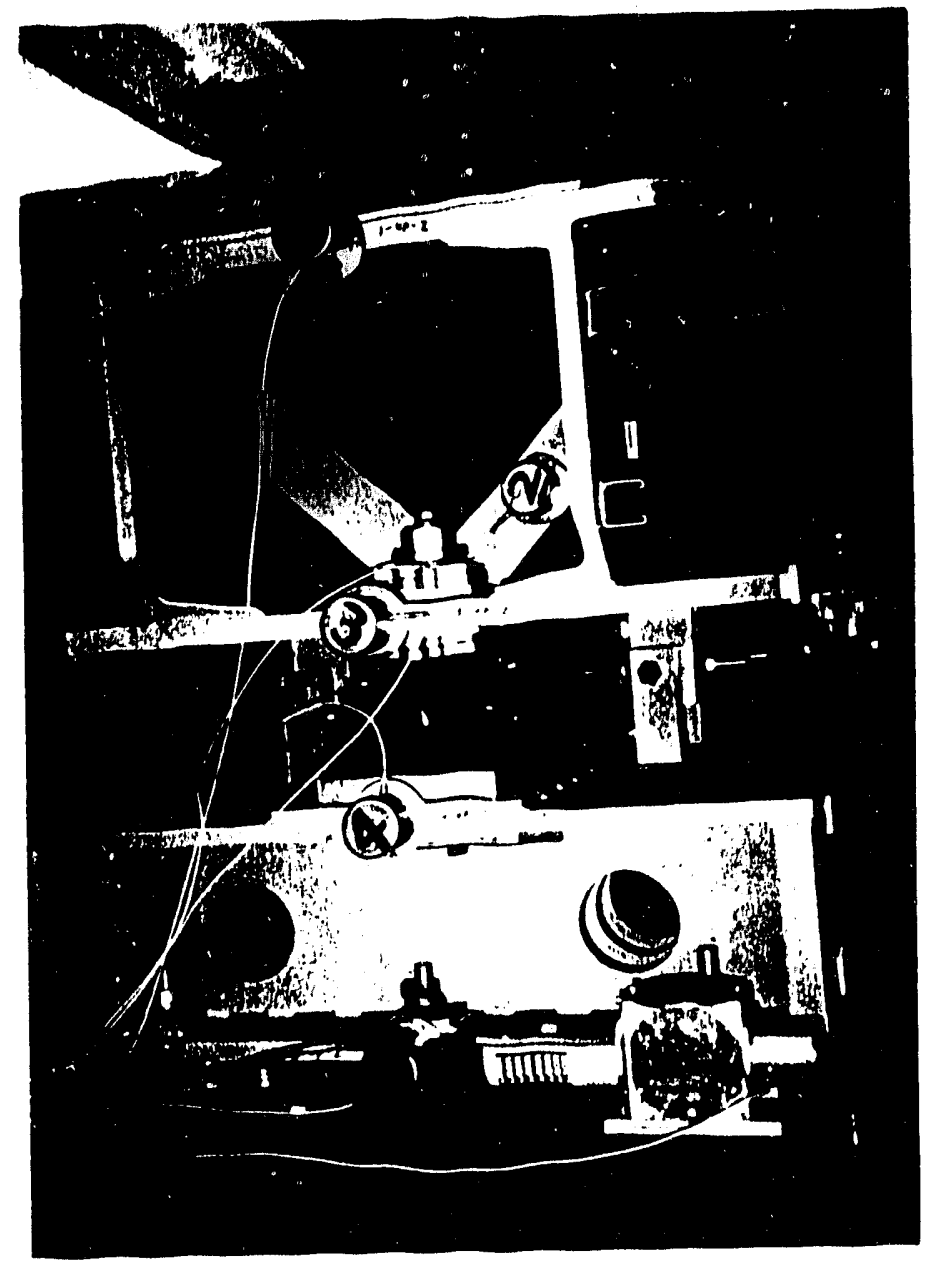

Fig. 5. Accelerometers located on girder/ pedestal system and oriented to measure Z-direction response: Girder A Pedestal set $\mathrm{A} /$ single-jack end 
3A114XU

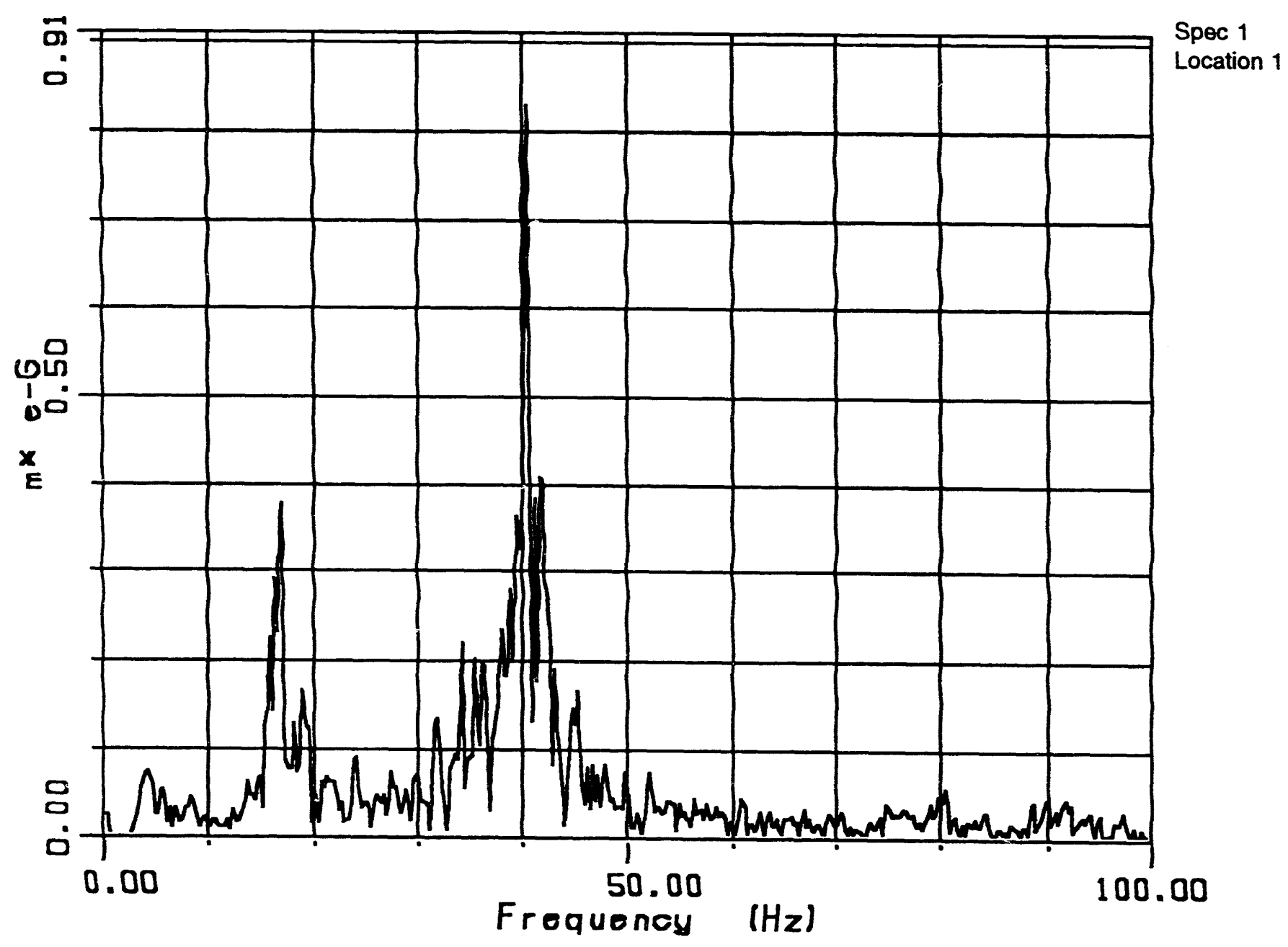

Fig. 6. Typical PSD of X-direction response to 0-to-100 Hz random excitation 
3A115XU

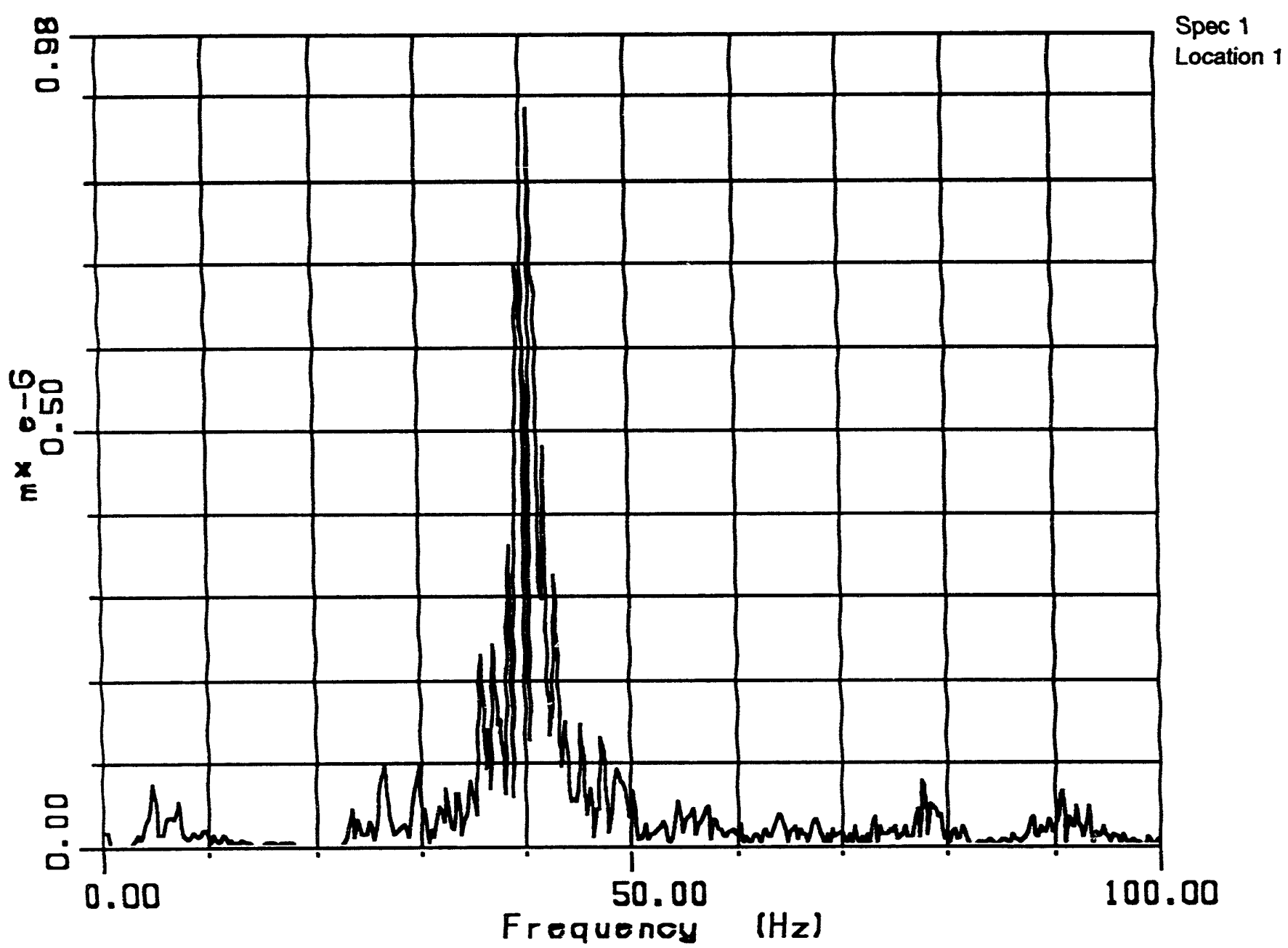

Fig. 7. Typical PSD of X-direction response to 25 -to- $100 \mathrm{~Hz}$ random excitation 


\section{A 126XU}

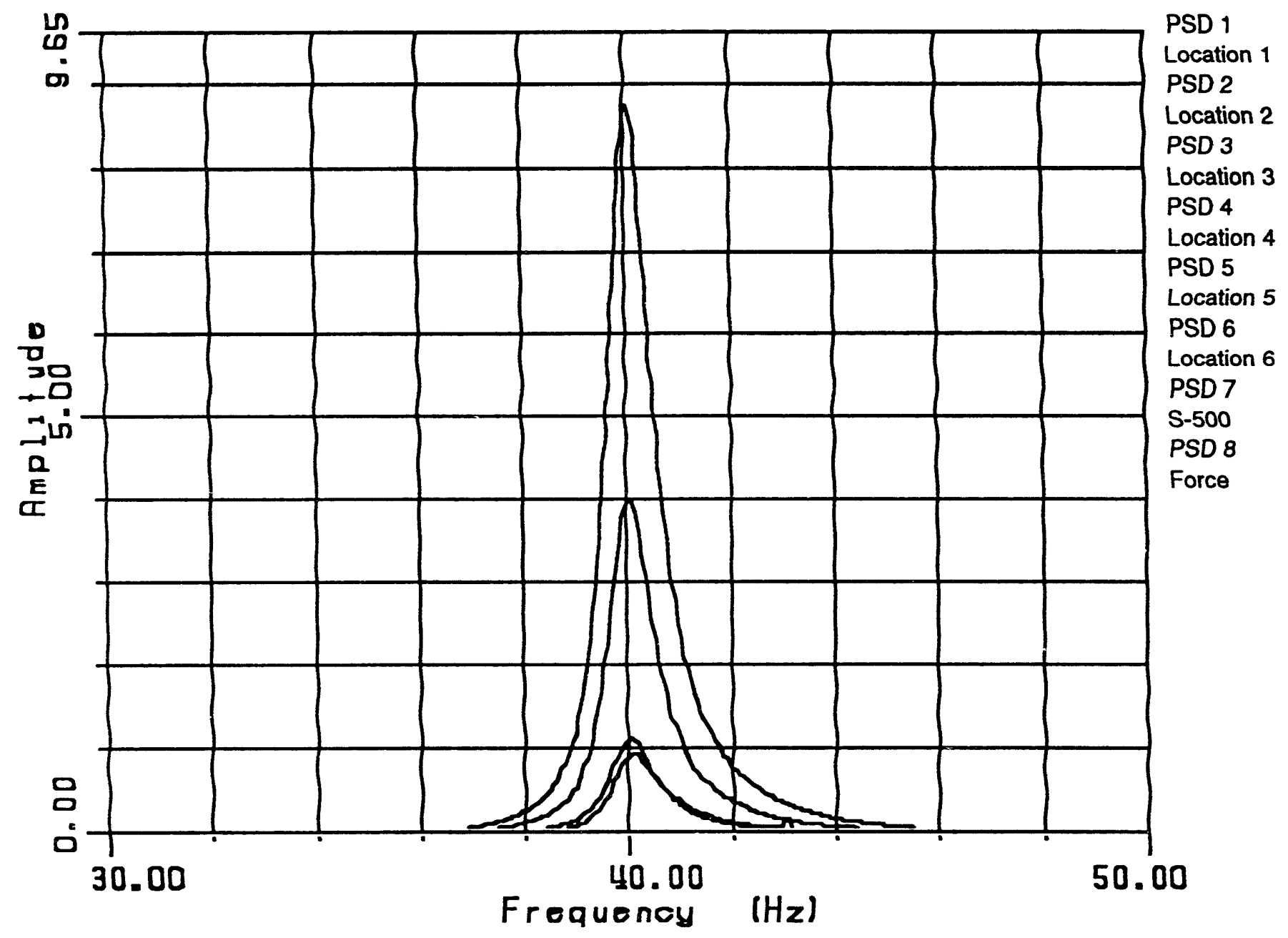

Fig. 8. Typical response to swept sine wave excitation as measured at different sensor locations 


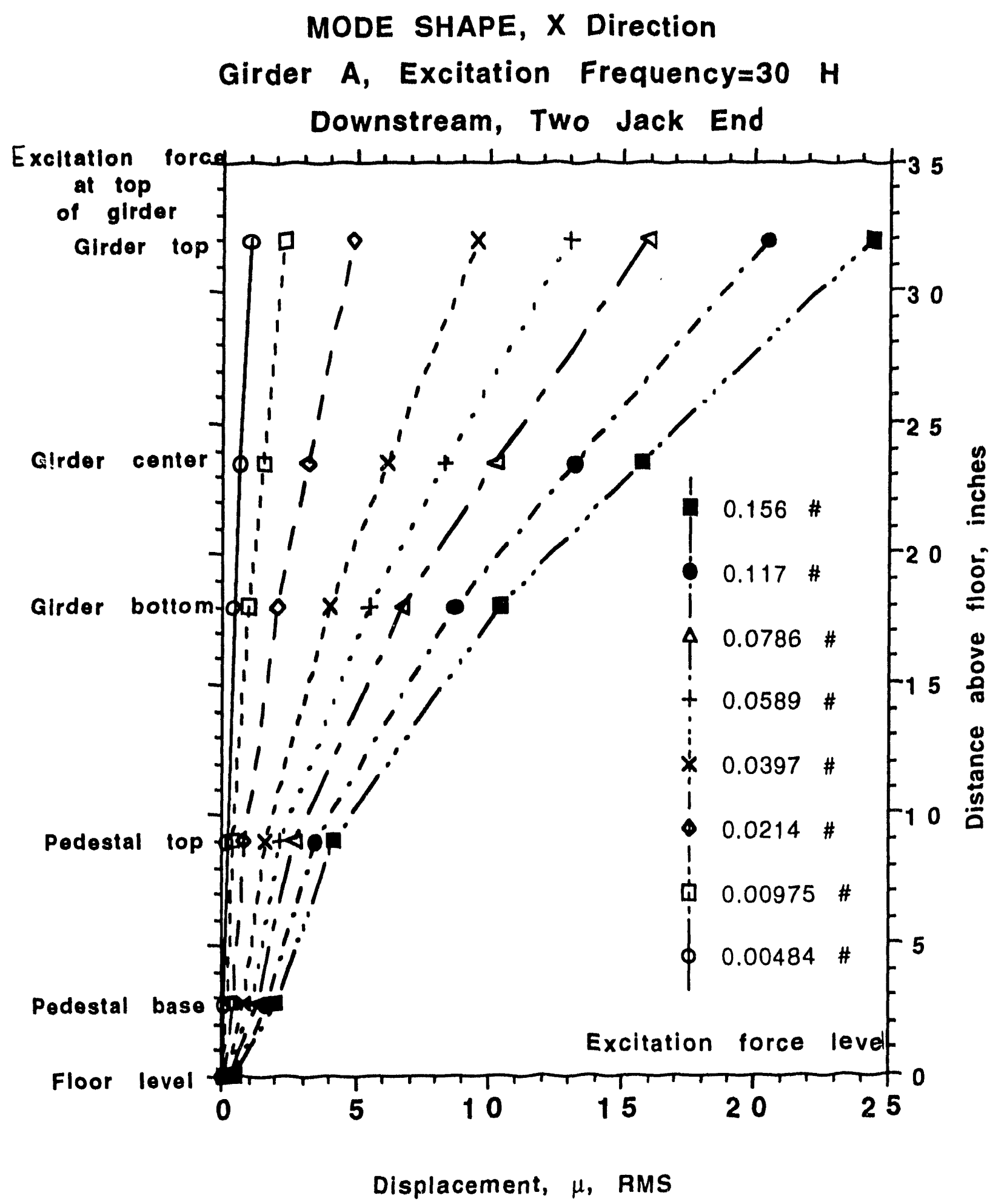

Fig. 9. Typical RMS displacement response for a range of sinusoidal excitation force levels 


\section{NORMALIZED MODE SHAPE, $X$ Direction}

Girder A, Exc. Freq. $=30 \mathrm{~Hz}$ Test 1

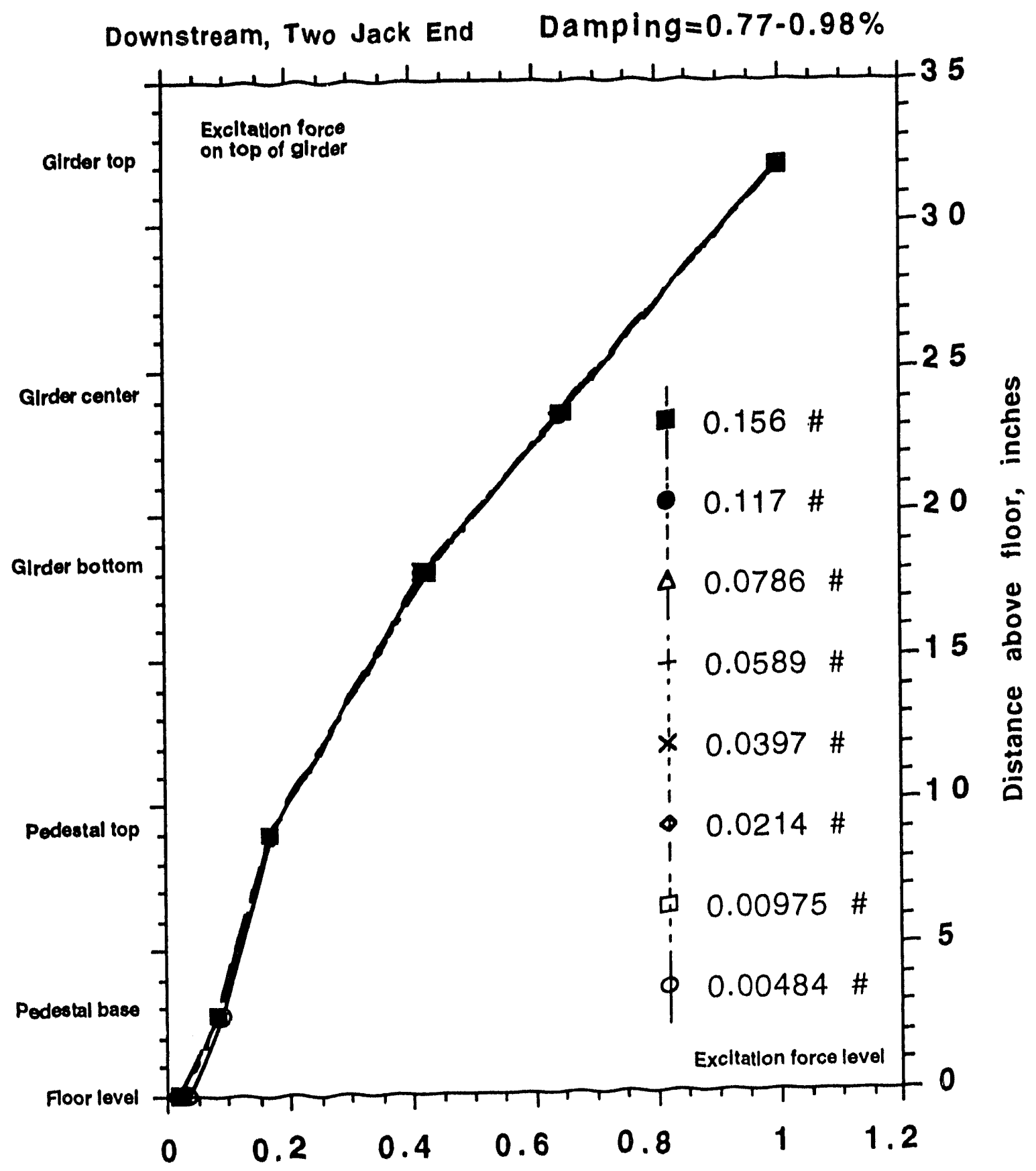

Fig. 10. X-direction mode: Girder A/Pedestal set A/shims alone 


\section{NORMALIZED MODE SHAPE, $X$ Direction}
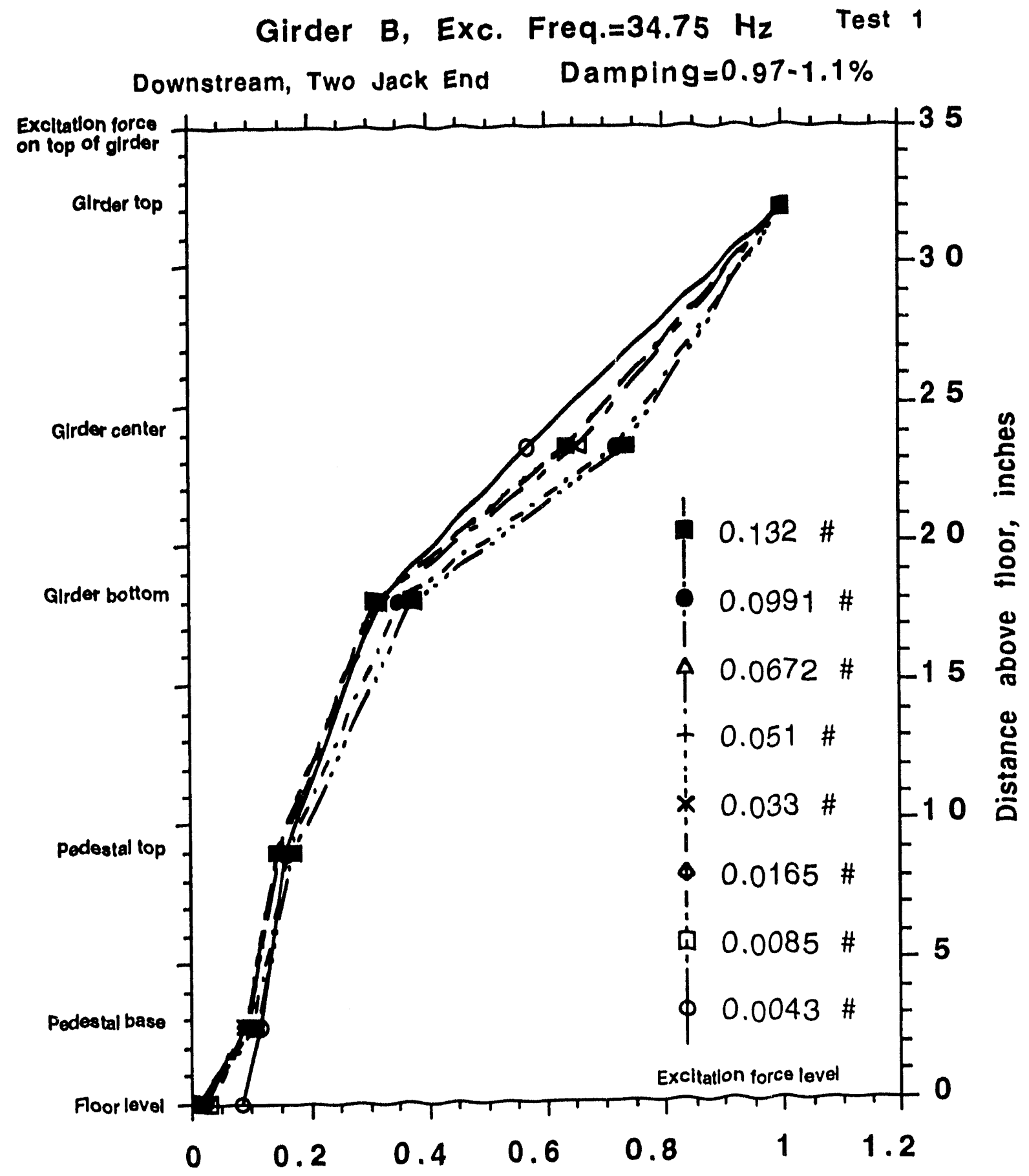

Fig. 11. X-direction mode: Girder B/Pedestal set B/shims alone 


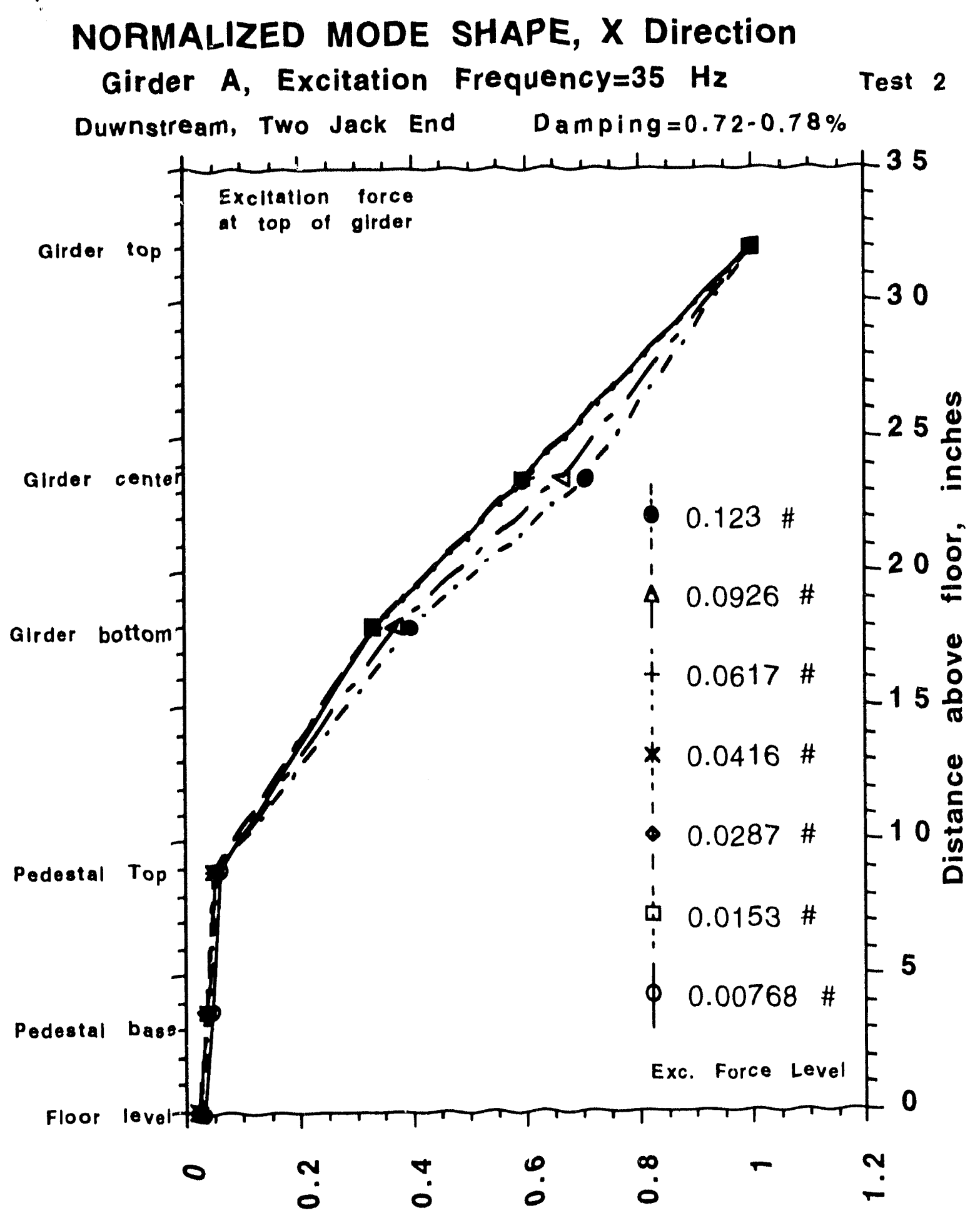

Fig. 12. X-direction mode: Girder A/Pedestal set $\mathrm{A} /$ shims and grout 


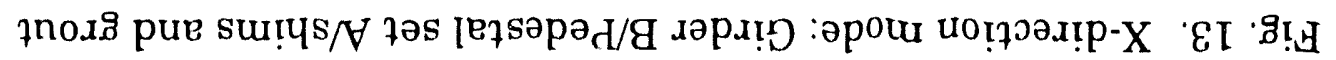

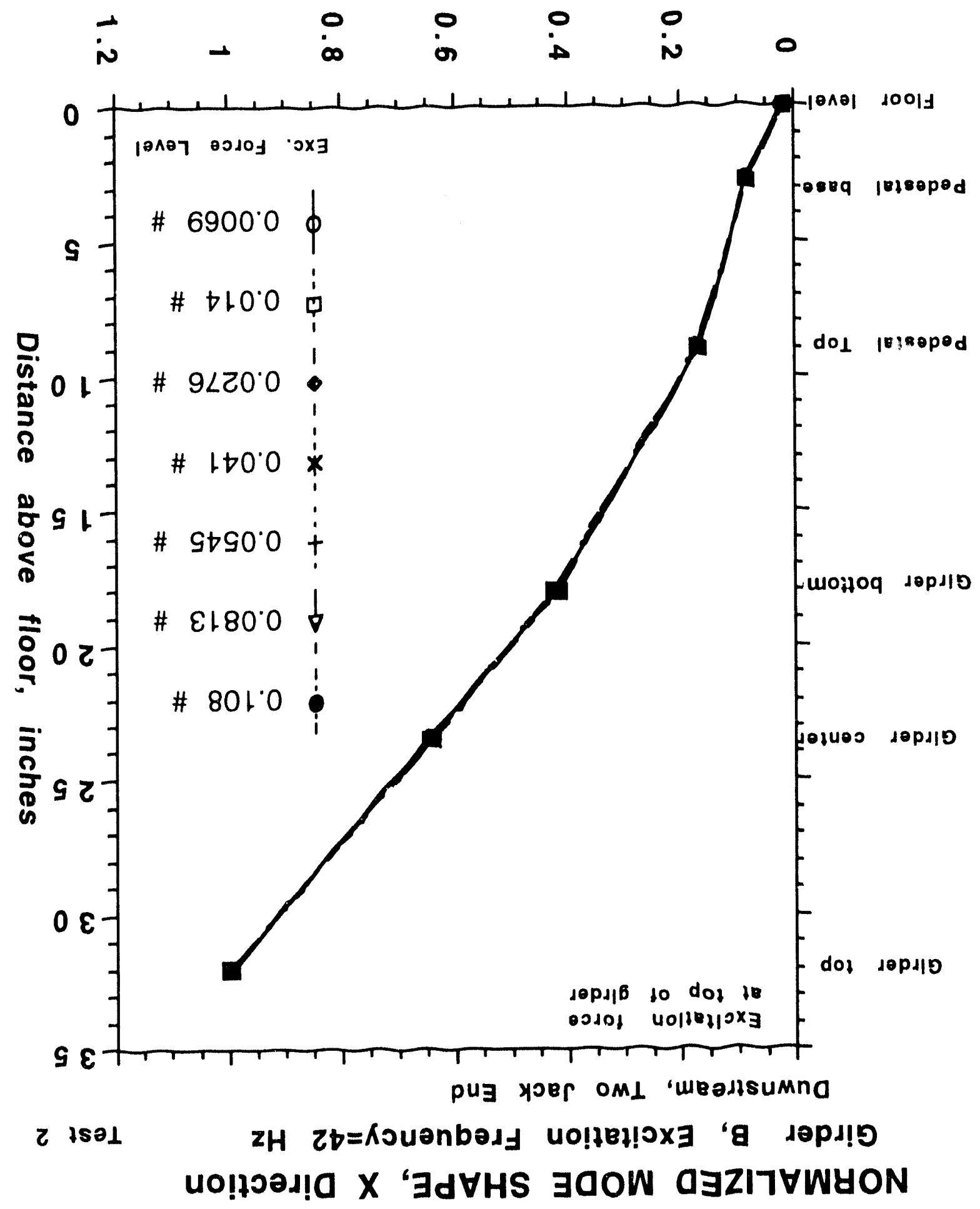


NORMALIZED MODE SHAPE, $X$ Direction

Girder A, Excitation Frequency $=40.5 \mathrm{~Hz} \quad$ Test 3

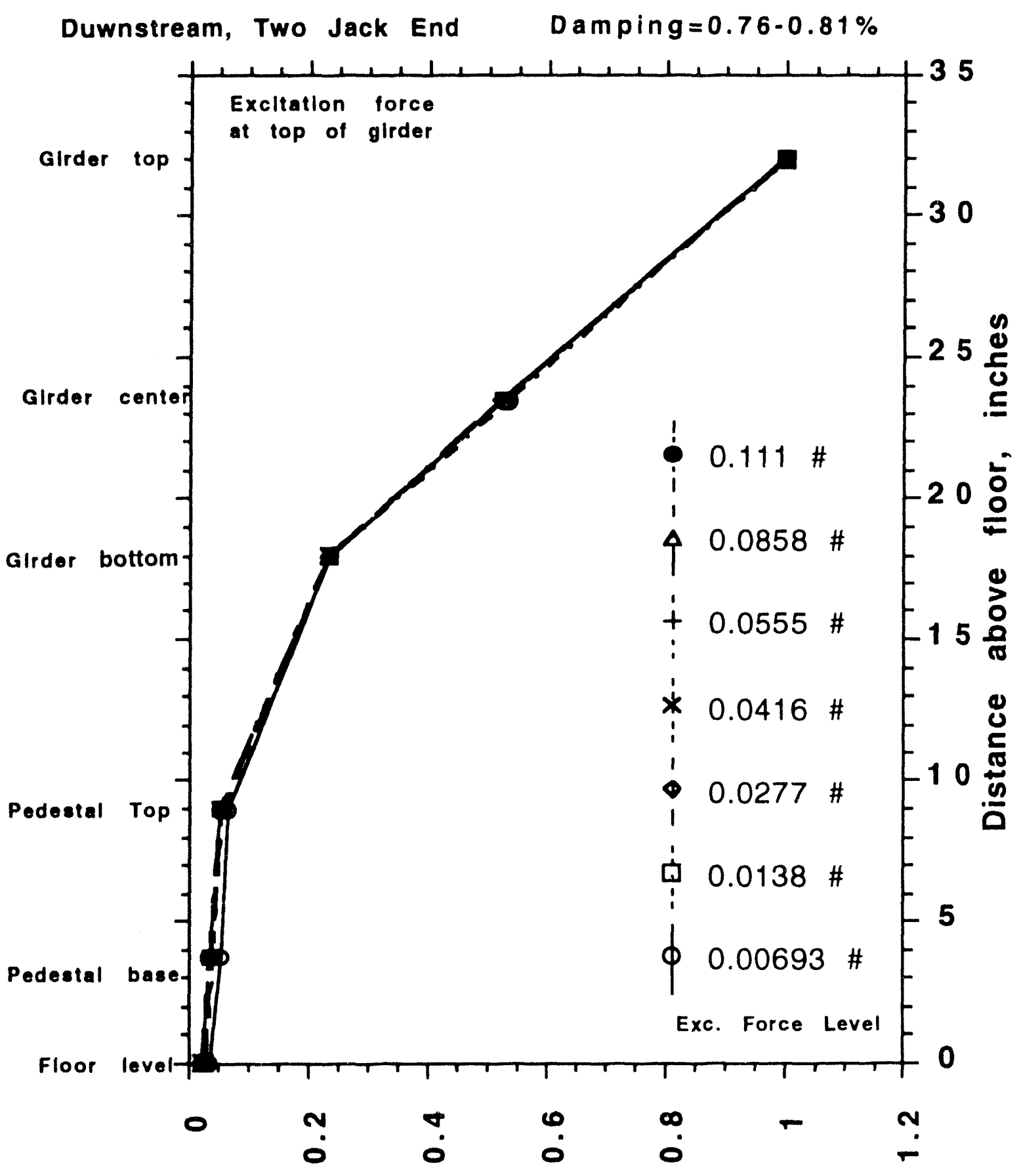

Fig. 14. X-direction mode: Girder A/Pedestal set B/grout alone 


\section{NORMALIZED MODE SHAPE, $X$ Direction}

\section{Girder B, Excitation Frequency $=40 \mathrm{~Hz} \quad$ Test 3}

Duwnstream, Two Jack End Damping=1.04-1.09\%

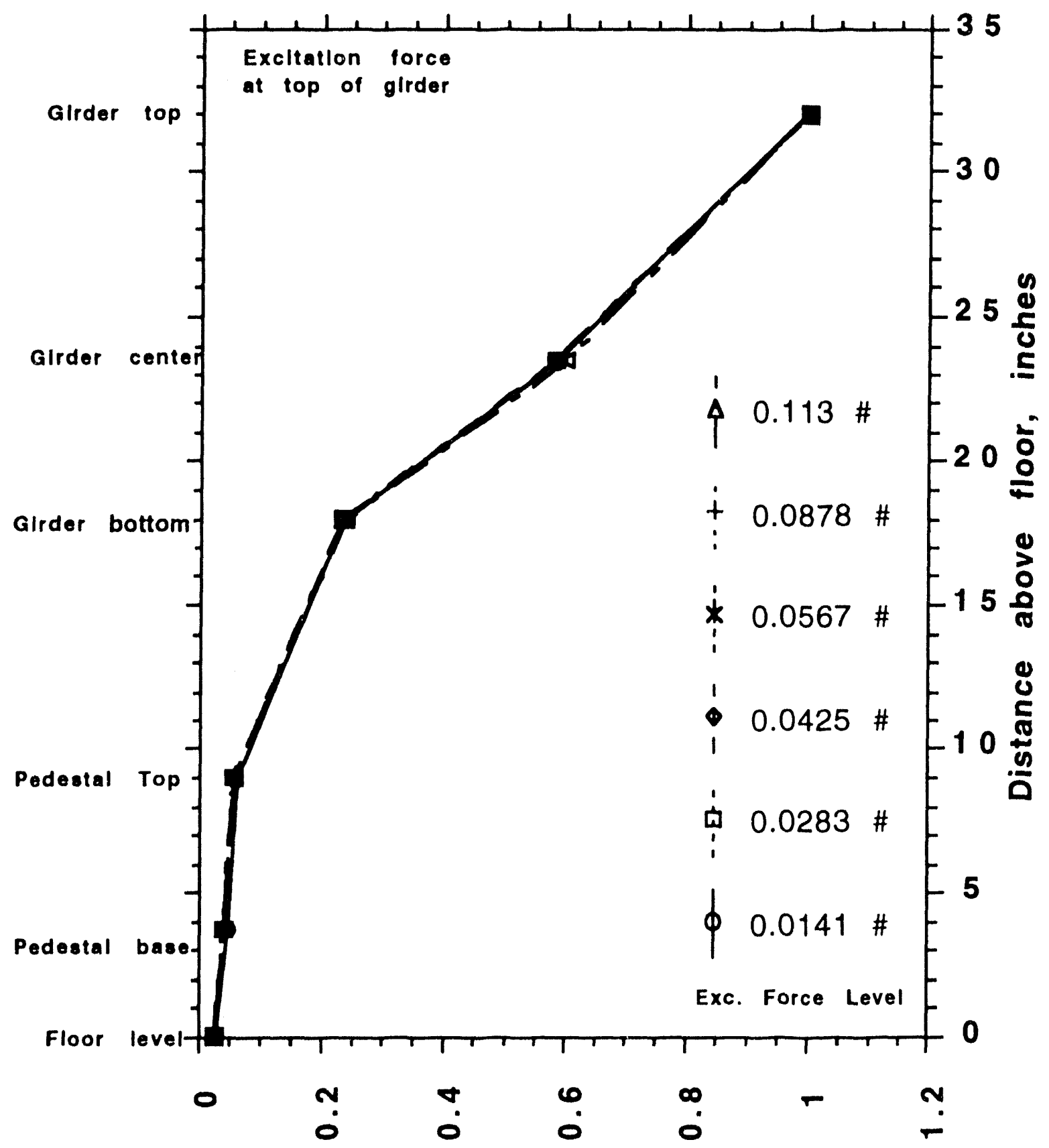

Fig. 15. X-direction mode: Girder B/Pedestal set B/grout alone 


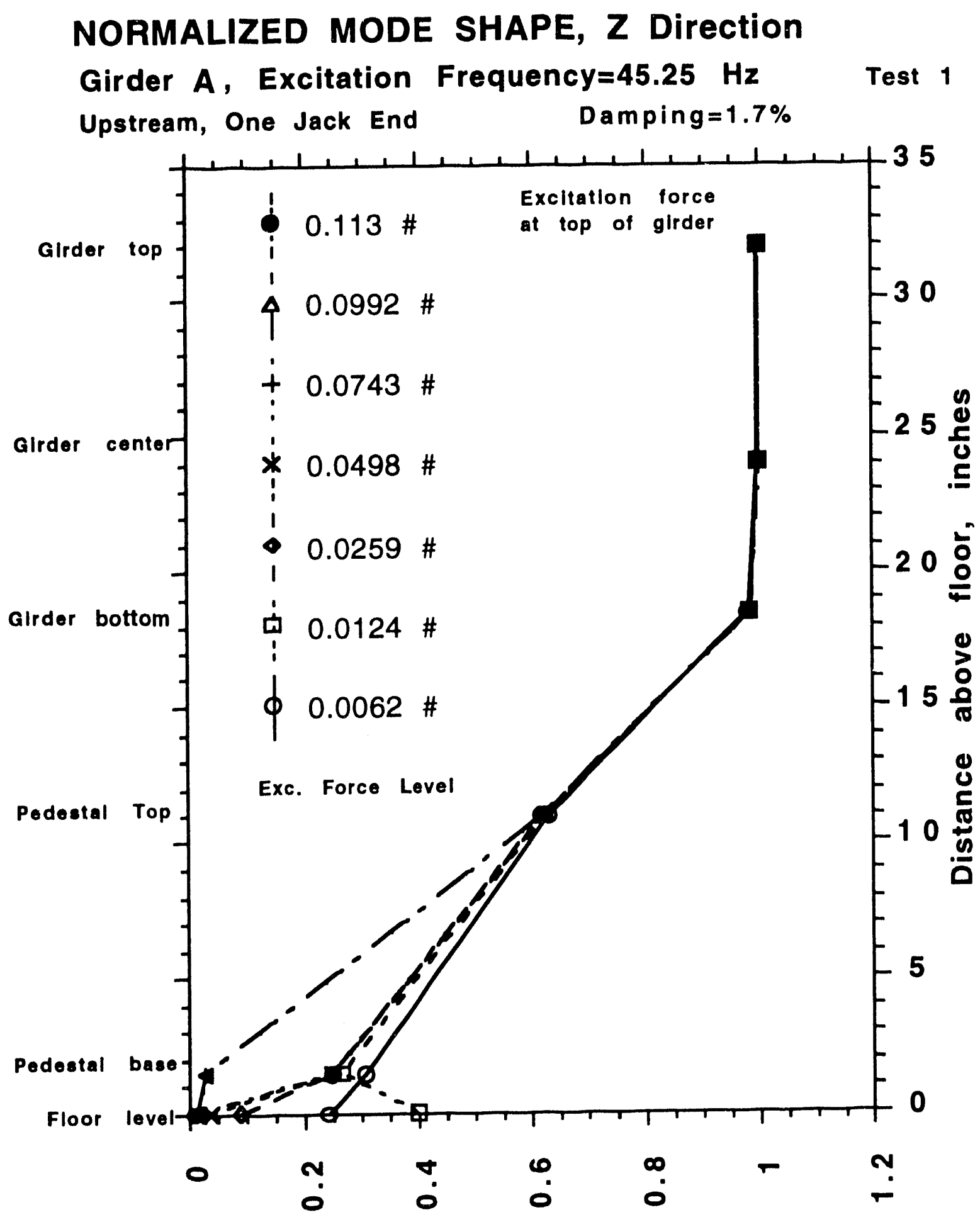

Fig. 16. Z-direction mode: Girder A/Pedestal set A/shims alone 
NORMALIZED MODE SHAPE, $Z$ Direction

Girder B, Excitation Frequency $=50.75 \mathrm{~Hz}$ Test 1

Upstream, One Jack End Damping=1.99-2.42\%

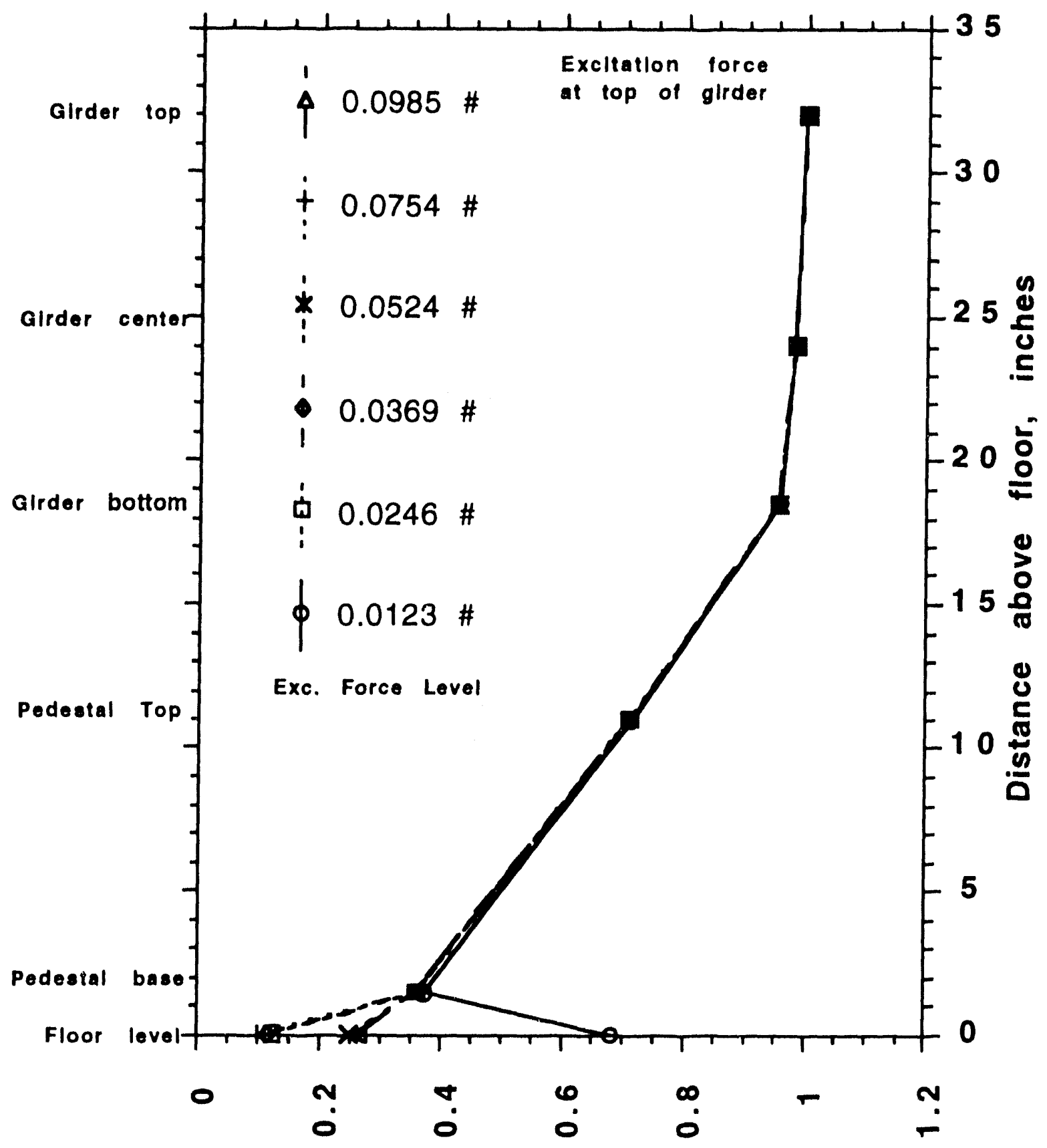

Fig. 17. Z-direction mode: Girder B/Pedestal set B/shims alone 
NORMALIZED MODE SHAPE, $Z$ Direction

Girder A, Exisitation Frequency=74.25 $\mathrm{Hz}$ Test 2

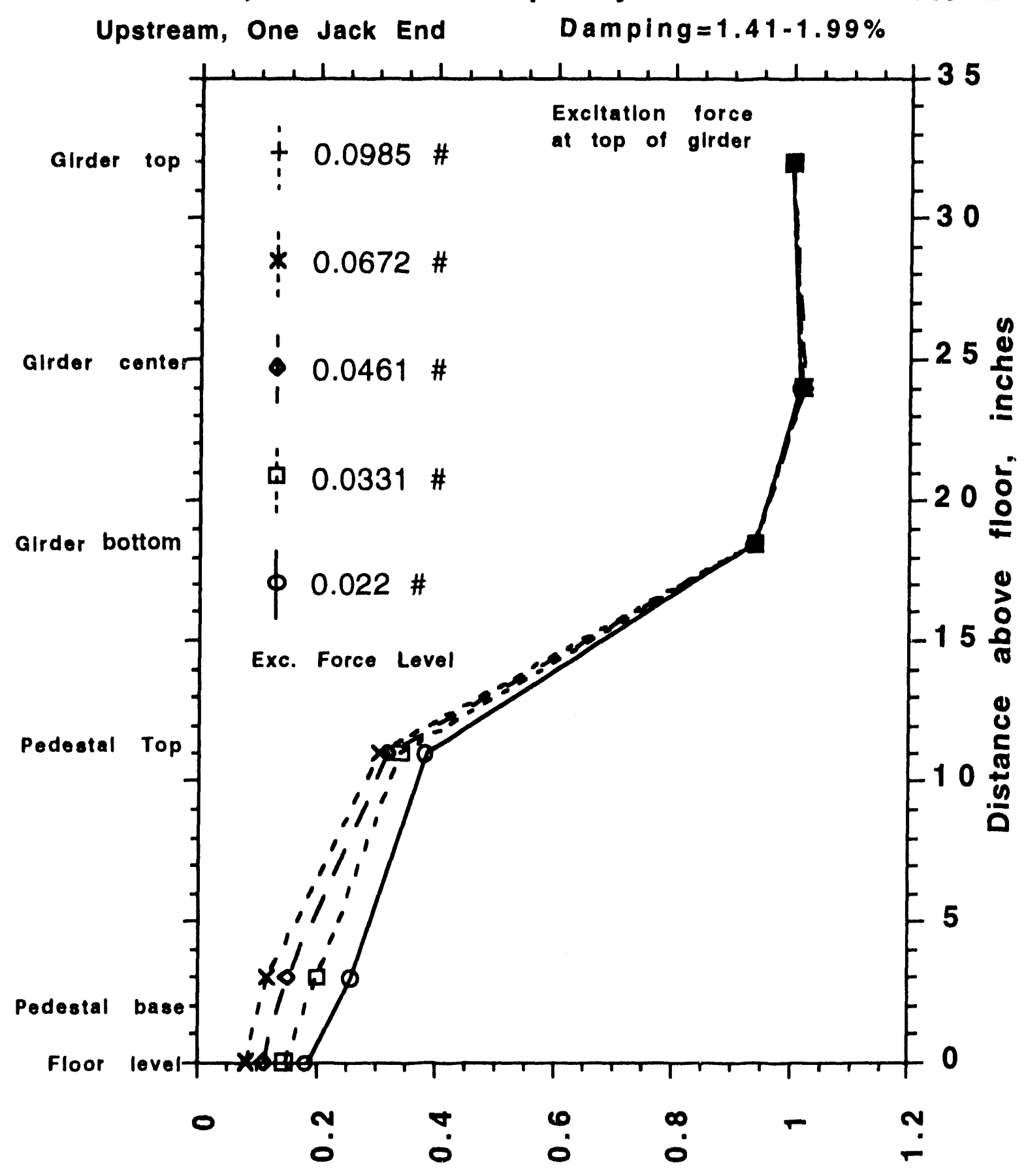

Fig. 18. Z-direction mode: Girder A/Pedestal set A/shims and grout 


\section{NORMALIZED MODE SHAPE, $Z$ Direction}

Girder B, Excitation Frequency $=82.5 \mathrm{~Hz}$ Test 2

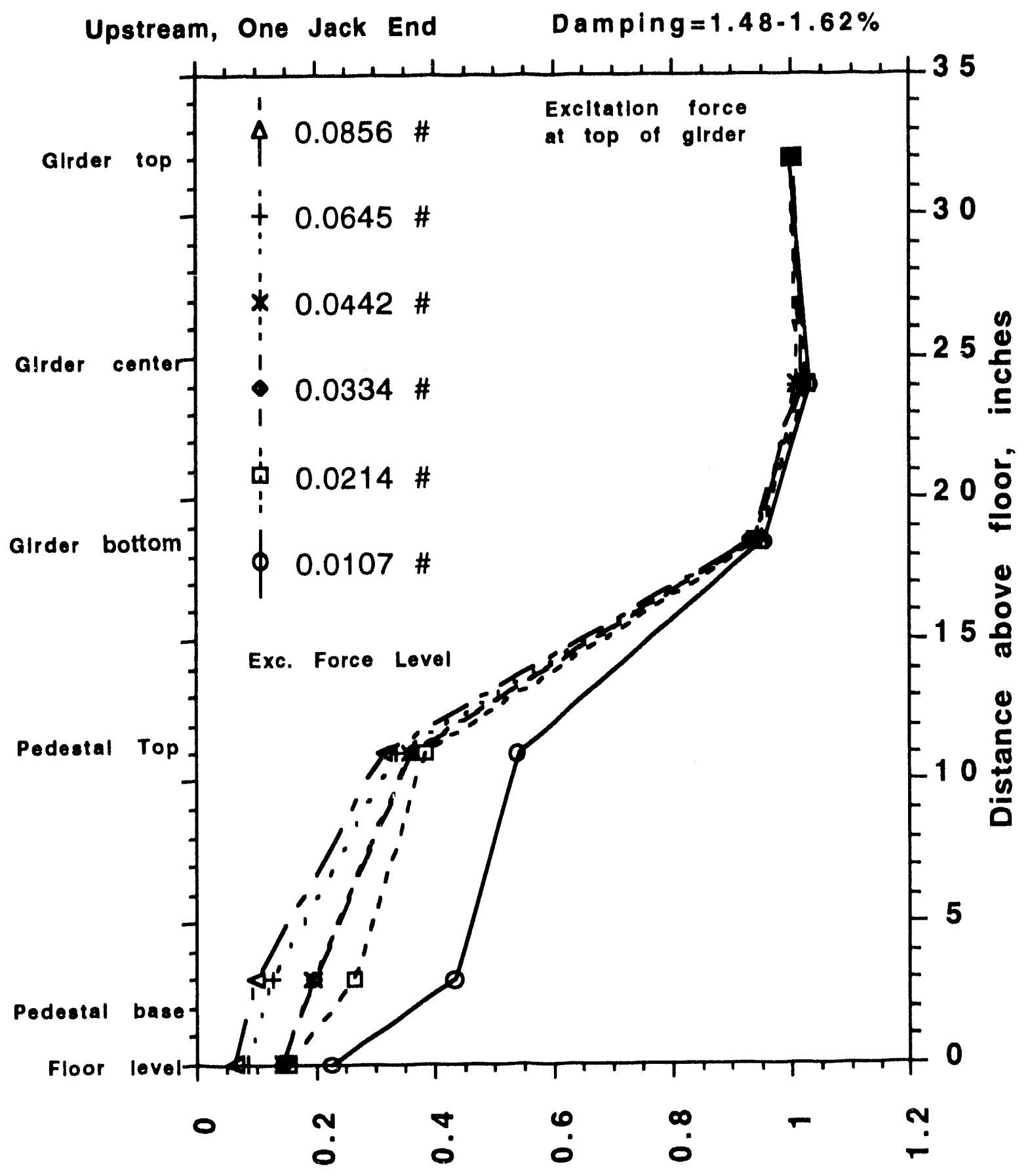

Fig. 19. Z-direction mode: Girder B/Pedestal set A/shims and grout 
NORMALIZED MODE SHAPE, $Z$ Direction

Girder A, Excitation Frequency $=79.5 \mathrm{~Hz}$ Test 3

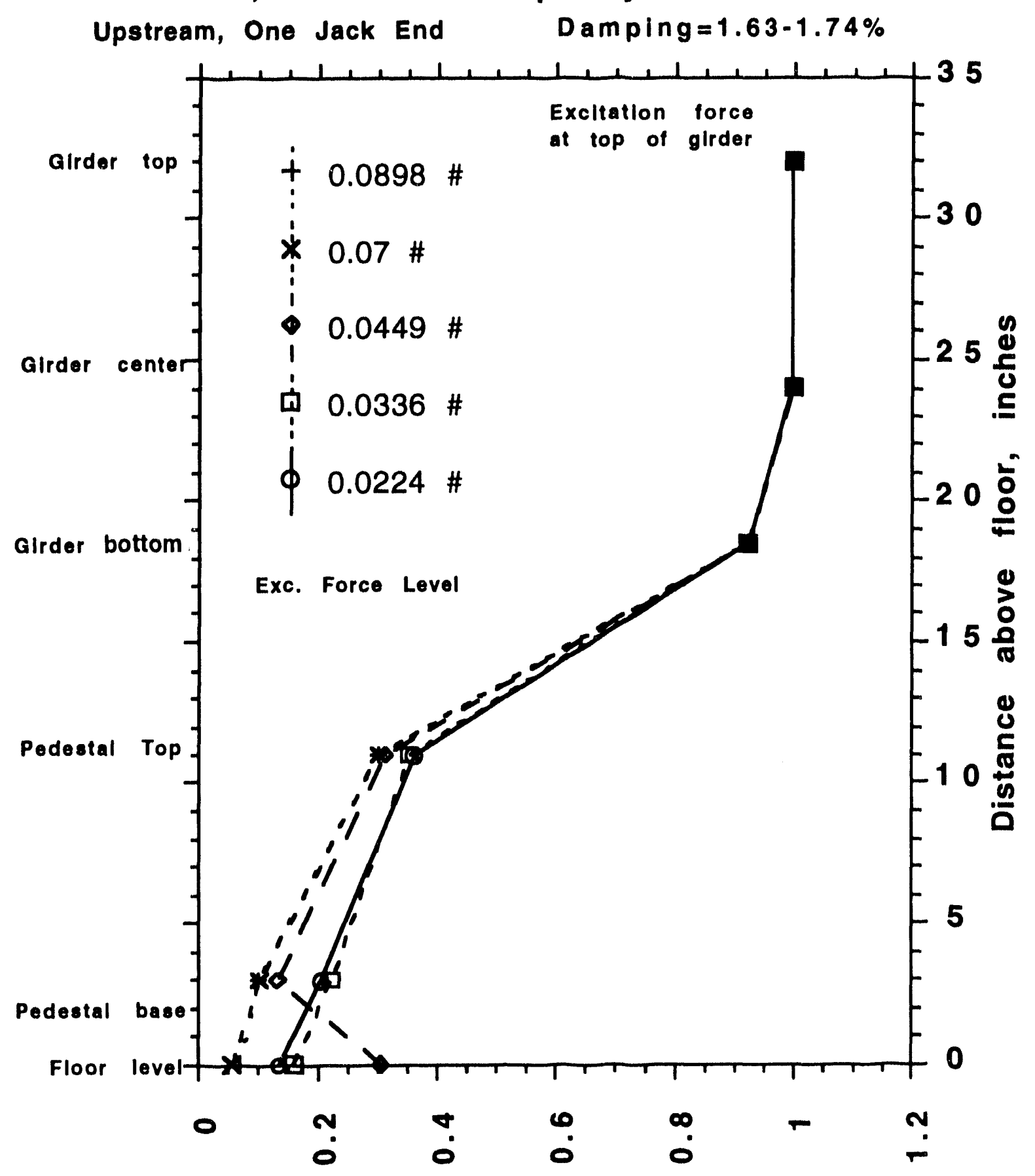

Fig. 20. Z-direction mode: Girder A/Pedestal set B/grout alone 
NORMALIZED MODE SHAPE, $Z$ Direction

Girder B, Excitation Frequency $=82.5 \mathrm{~Hz} \quad$ Test 3 Upstream, One Jack End Damping $=1.41 .1 .46 \%$

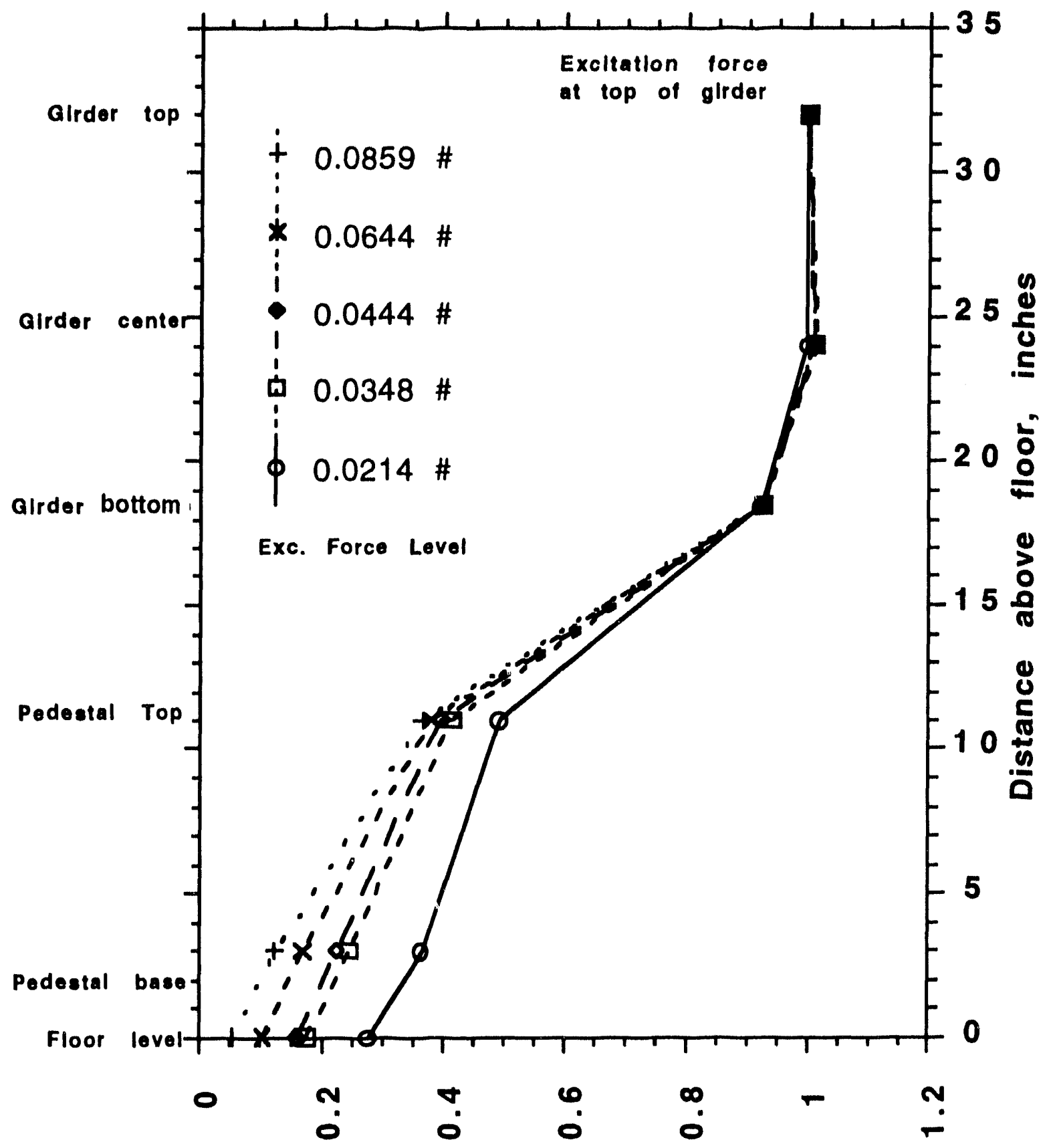

Fig. 21. Z-direction mode: Girder B/Pedestal set B/grout alone 


\section{NORMALIZED MODE SHAPES, $X$ Direction}

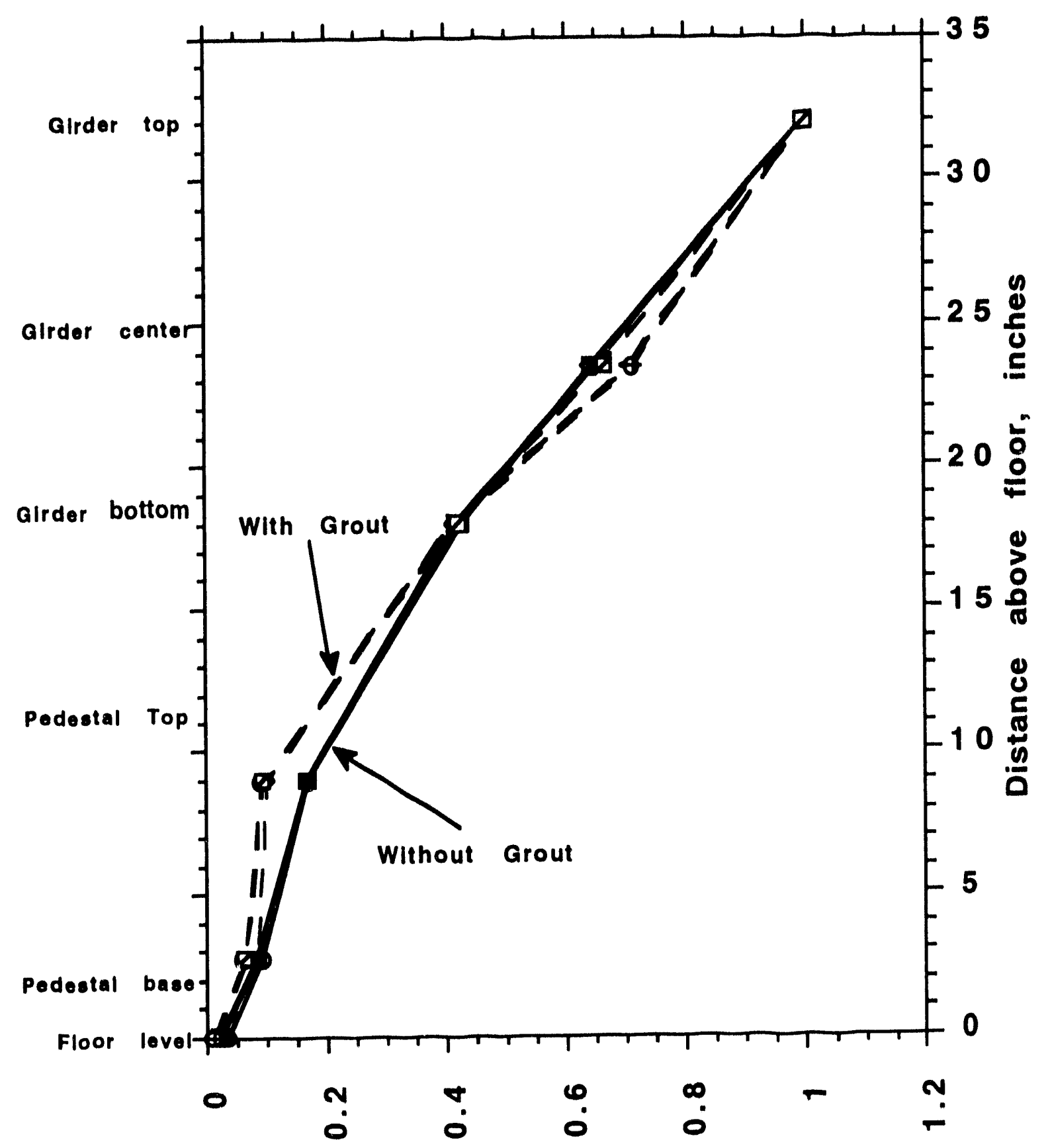

Fig. 22. A comparison of X-direction mode shapes for the conditions with (Figs. 12 and 14) and without (Fig. 10) grout 


\section{MODE SHAPE COMPARISON, X AND $Z$ Direction}

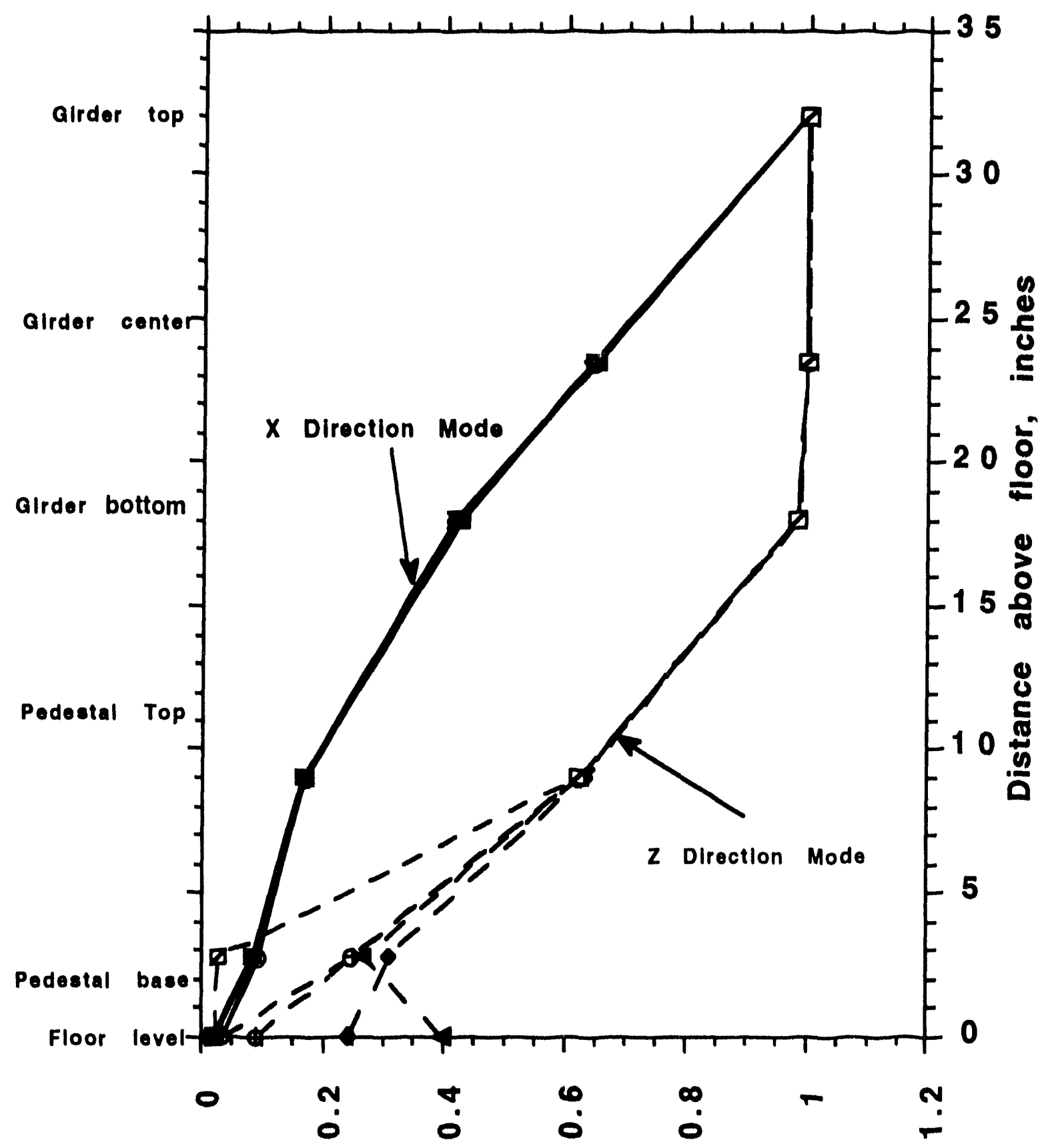

Fig. 23. A comparison of X- (Fig. 10) and Z-direction (Fig. 16) modes for the case of shims alone 


\section{NORMALIZED MODE SHAPES, $Z$ Direction}

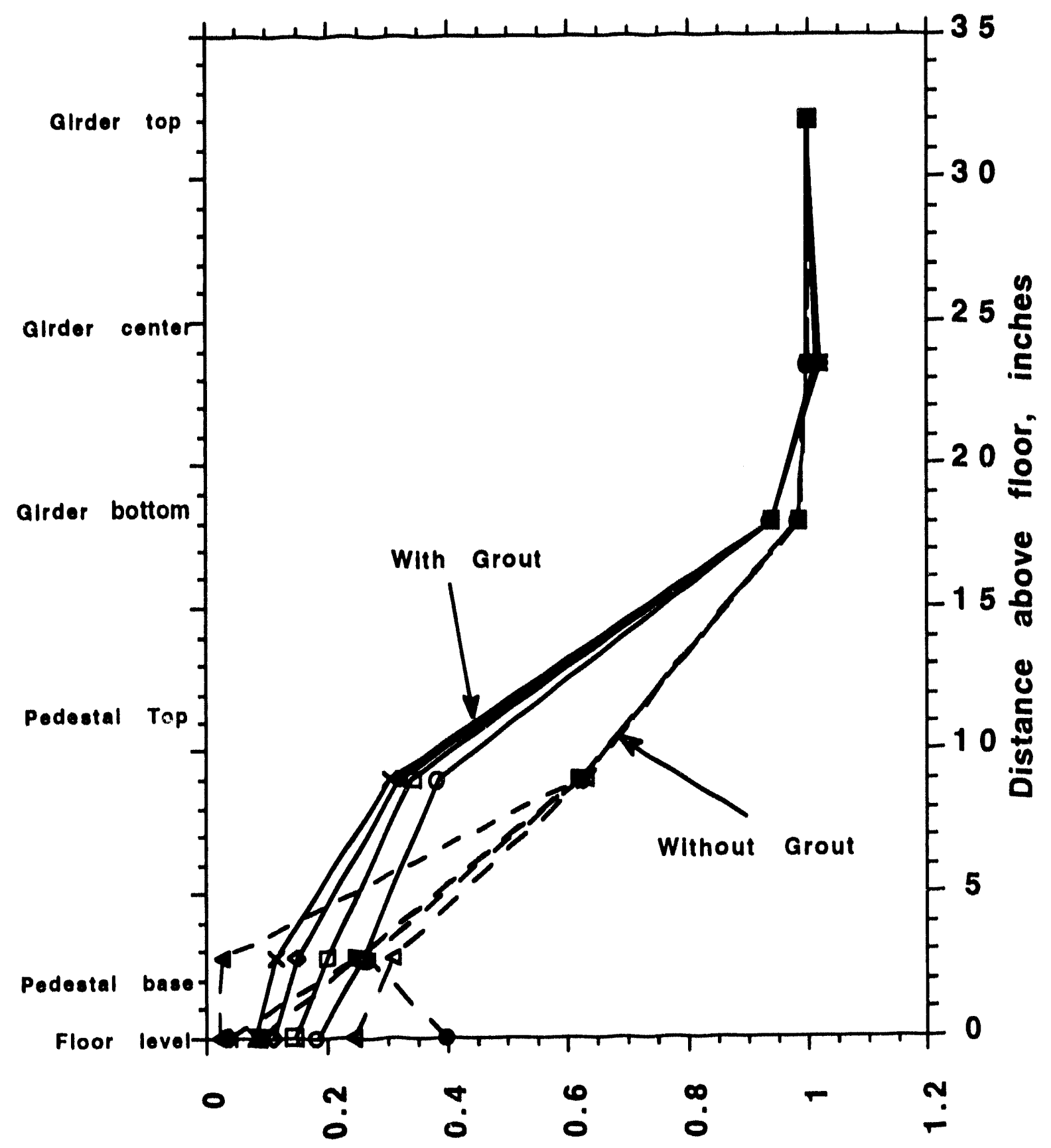

Fig. 24. A comparison of Z-direction mode shapes for the conditions with (Figs. 18 and 20) and without (Fig. 16) grout 


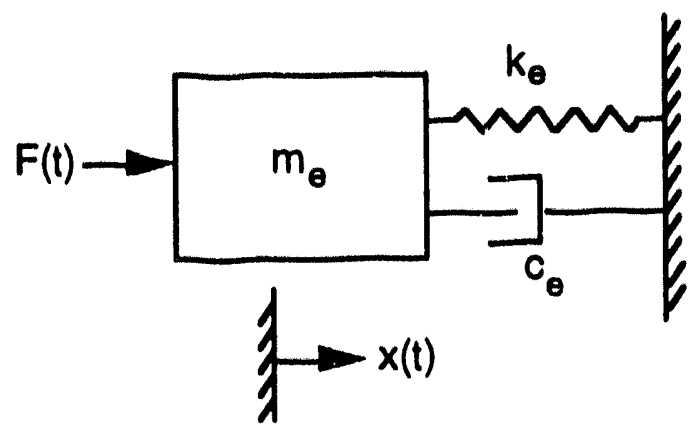

where, $k_{\theta}$ is equivalent spring constant

$c_{e}$ is equivalent damping

$\mathrm{m}_{\theta}$ is equivalent mass

natural frequency $\omega_{n}=2 \pi f_{n}=\sqrt{\frac{k_{e}}{m_{e}}}$

for sinusoidal excitation,

$$
\begin{aligned}
& F(t)=F_{0} \sin \omega t \\
& x(t)=X \sin (\omega t-\phi)
\end{aligned}
$$

Fig. 25. Equivalent single-degree-of-freedom model 


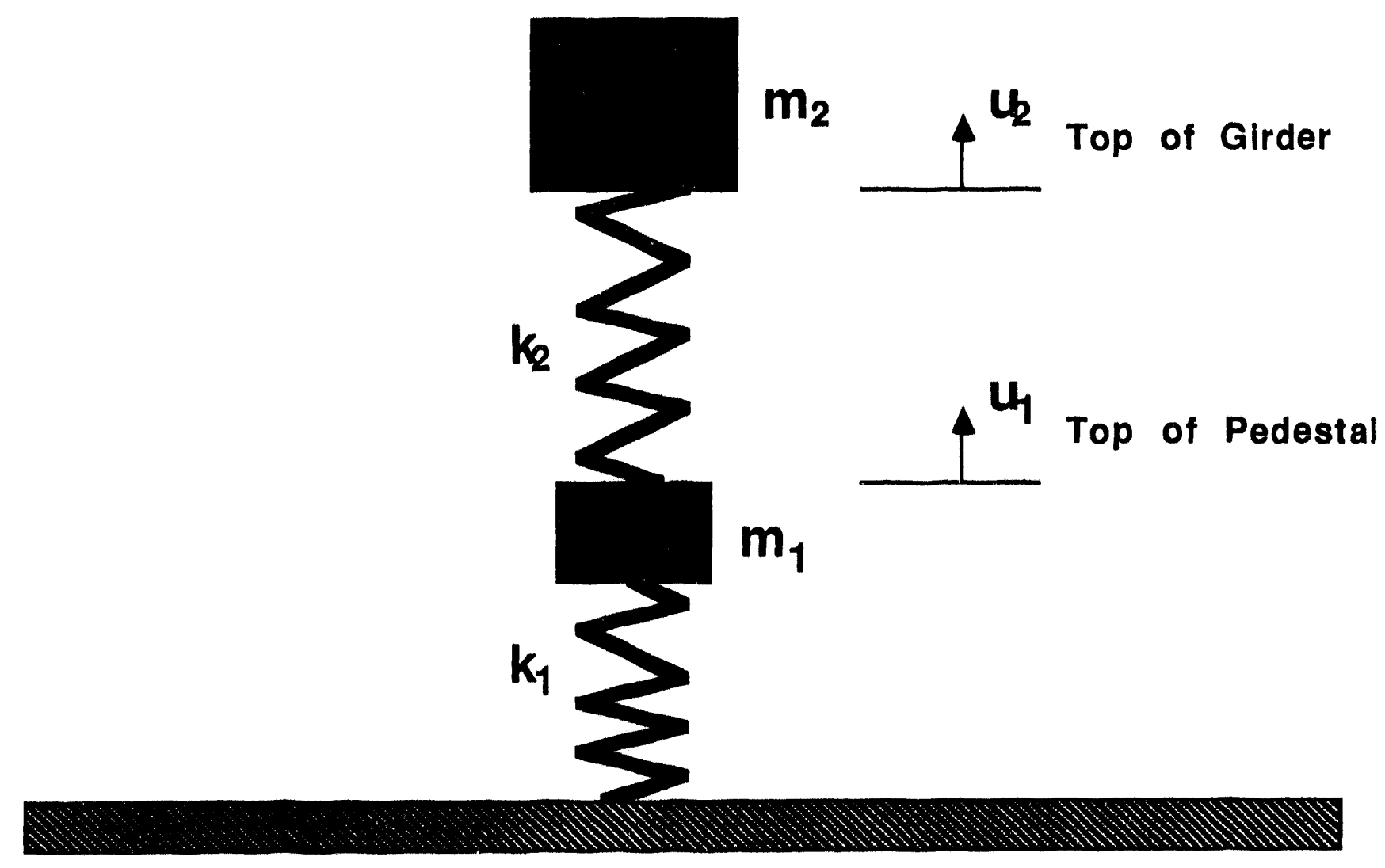

Fig. 26. Equivalent two-degree-of-freedom model 

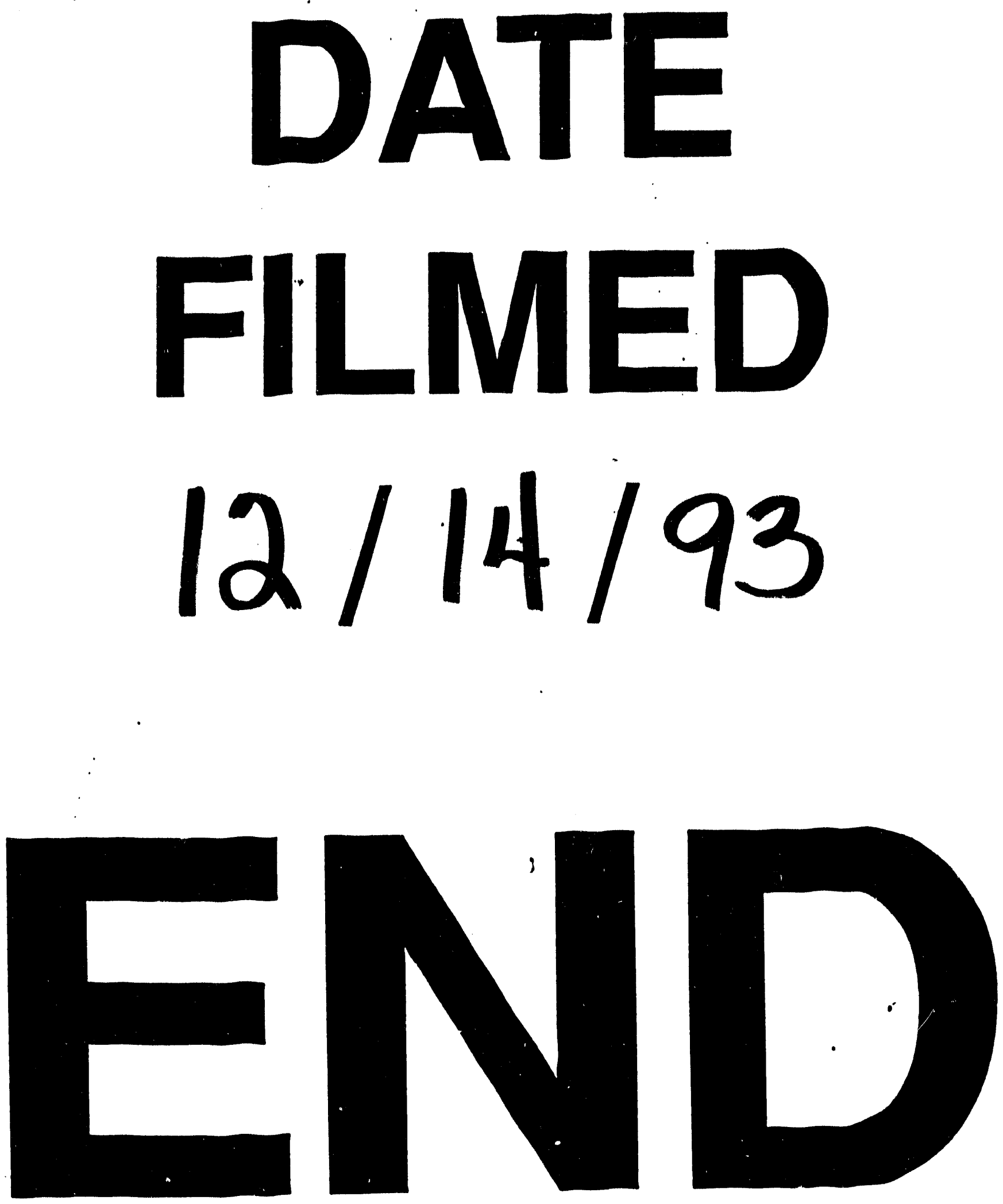